\title{
DOUBLE FERTILIZATION IN BARLEY AND THE CYTOLOGICAL EXPLANATION FOR HAPLOID EMBRYO FORMATION, EMBRYOLESS CARYOPSES, AND OVULE ABORTION
}

\author{
by \\ H. LLOYD MOGENSEN \\ Department of Biological Sciences, Northern Arizona University, \\ Box 5640, Flagstaff, Arizona 86011, USA \\ and \\ Department of Physiology, Carlsberg Laboratory, \\ Gamle Carlsberg Vej 10, DK-2500 Copenhagen Valby ${ }^{1}$ \\ Visiting professor, June 1st to August 1st, 1982
}

Keywords: Hordeum vulgare, parthenogenesis, haploid initiator mutant, pollen tube, egg cell, central cell, synergids, sperm cells

The progeny of an induced barley mutant has recently been shown to produce a relatively high percentage of caryopses containing haploid embryos. In addition, some caryopses have a full complement of endosperm, but lack an embryo, and still other ovules abort at an early stage. The study reported here was initiated to investigate the embryological basis of these unusual phenomena. Since the majority of the ovules studied showed normal double fertilization, a built-in control was provided and, therefore, this process is also described. The pollen tube delivers the two male gametes to the embryo sac by first growing through the micropyle of the inner integument, then between nucellar cells before discharging into the degenerate synergid. Double fertilization is effected after the sperm cells exit the degenerate synergid and enter the intercellular space between the egg apparatus and the central cell. The lack of a cytoplasmic sheath around the sperm nucleus within the egg, the absence of any identifiable male organelles in the egg-zygote cytoplasm, and the presence of a cytoplasmic sheath in the intercellular space outside the zygote at the point where the sperm nucleus had entered, suggest that no male cytoplasm enters the egg during the process of syngamy. Haploid embryos arise from the unfertilized egg. In these ovules, triple fusion of the polar nuclei and one sperm occurs normally, but the other sperm fails to enter the egg even though it reaches the intercellular space just outside the female gamete. Embryoless caryopses appear to result from a similar condition, i.e., the lack of syngamy accompanied by triploid endosperm formation. However, in this case, the egg does not continue to develop into an embryo. The absence of polar nuclei or the failure of triple fusion even though the egg may be fertilized, results in the ultimate abortion of some ovules.

Abbreviations: PIPES = 1,4-piperazinediethane sulfonic acid. 


\section{INTRODUCTION}

The spontaneous production of haploid embryos by the progeny of an induced barley mutant has recently been reported by HAGBERG and HaGberG (13). Caryopses containing haploid embryos occur in varying frequencies up to $40 \%$ or more, are of full size, and appear normal in every respect. Seedlings resulting from haploid embryos are vigorous and grow to maturity without special treatment. When the chromosome number is doubled via colchicine, the plants are quite fertile and, in turn, produce more haploid embryos. In addition to haploid embryo production, some ovaries develop into full-size caryopses with a complete endosperm, but no embryo, while others abort at an early stage.

Besides being a potentially valuable tool for plant breeders, this barley mutant is of special interest from an embryological stand point. Questions that immediately come to mind are: What is the embryological basis behind haploid embryo formation? Is the endosperm of caryopses with haploid embryos composed of normal triploid tissue? Would an embryological study of the haploid phenomenon offer any insights into basic mechanisms involved in normal double fertilization? How are embryoless caryopses formed? Why do some ovules abort at an early stage? The investigation being reported here was initiated for the purpose of answering these questions.

Since normal double fertilization occurred in the majority of the cases studied, a built-in standard was provided. For this reason, and the fact that double fertilization has not been previously reported for barley at the electron microscope level, some details of this process are also described in the present report.

\section{MATERIALS AND METHODS}

Plants used for this study were derived from the homozygous recessive hap (haploid initiator) mutant stocks of Hordeum vulgare L. variety Bonus according to the procedures described by HAGBERG and HAgBerg (13). The plants were grown in individual pots containing standard potting soil in a glasshouse under controlled, optimum conditions (15) at the experimental farm of Carlsberg Plant Breeding, Hyldagergård, Denmark and the Swedish University of Agricultural Sciences, Department of Plant Breeding, at Svalöv, Sweden. Some plants were also grown in a growth chamber at Northern Arizona University, Flagstaff, Arizona under similar conditions.

Florets were emasculated and bagged (15) two days before hand-pollinations were performed. At timed intervals after pollination (all spikes were rebagged after pollination), carpellary tissue was trimmed with a razor blade under buffer solution (either phosphate buffer, $\mathrm{pH} 7.4$ or PIPES buffer, pH 7.8) and the exposed ovules were fixed in $4 \%$ glutaraldehyde in either phosphate buffer, pH 7.4 or PIPES buffer, pH 7.8. Some ovules were also fixed in $4 \%$ glutaraldehyde in sodium cacodylate buffer at $\mathrm{pH}$ 7.2. Fixation times included: (a) before pollination; (b) 30 minutes to 75 minutes after pollination, with individual ovules being fixed every 3 to 5 minutes during this period; (c) 1 hour to 1 hour and 45 minutes after pollination with individual fixations every 3 to 5 minutes during this period; (d) 2 hours to 2 hours and 45 minutes post-pollination, with individual fixations every 3 to 5 minutes during this period; and (e) 4 hours to 4 hours and 45 minutes post-pollination, with fixations every 3 to 5 minutes during this period. Two additional fixation times, with all ovules fixed simultaneously, were made at 6 hours and 5 days post-pollination.

After 6 hours in glutaraldehyde at room temperature, the tissue was rinsed in buffer ( 2 hours, 3 changes) and post-fixed in $2 \%$ osmium tetroxide ( 2 hours at room temperature) in respective buffers and $\mathrm{pH}$ used for the glutaraldehyde fixation. Following a two hour rinse ( 3 changes) in distilled water, the tissue was held at $4^{\circ} \mathrm{C}$ overnight, then dehydrated in an ethanol series, changed to absolute acetone, and embedded in Spurr's resin.

Seventy-five ovules were thick-sectioned (3 $\mu \mathrm{m})$ with a glass knife and first observed with phase contrast microscopy. After photographing the desired thick section, it was re-embedded at the tip of an epoxy block according to a procedure described elsewhere (21), and ultrathin sectioned. Ultrathin sections were collected on single slot $(1 \mathrm{~mm} \times 2 \mathrm{~mm})$ grids and stained with an LKB Ultrostainer for 1 hour in uranyl acetate followed by 1 hour in lead citrate. Electron microscopy was accomplished with a Siemens 102 or a 
JEM-7A electron microscope. Some thick sections, not used for re-embedding, were stained with basic fuchsin and methylene blue (30). Chromosome counts were made from squashes of developing embryo and endosperm tissue that had been fixed in 3:1 ethyl alcohol and glacial acetic acid and stained with aceto-carmine.

\section{RESULTS}

\subsection{Normal double fertilization}

Pre-Syngamy. The mature embryo sac, before pollination, consists of two synergids and an egg cell at the micropylar end, a large, vacuolate central cell with two polar nuclei located at the chalazal end of the egg apparatus, and a cluster of several antipodal cells situated chalazally or somewhat to the side (Figures 1, 2, 5). Within one hour after pollination, several pollen tubes reach the micropylar end of the ovule and one enters the embryo sac by first growing through the micropyle of the inner integument, then continuing between nucellar cells and into the degenerate synergid via its filiform apparatus (Figures $2,5,6,7,8)$. Once in the degenerate synergid cytoplasm, the pollen tube discharges two sperm cells along with pollen tube cytoplasm which contains numerous, typical polysaccharide spheres (31) and some starch grains (Figure 8). No unequivocal example of a vegetative nucleus was seen in the degenerate synergid in this study. After pollen tube penetration, dense, osmiophilic areas are seen extending from the tip of the degenerate synergid around the chalazal end of the egg. This material is apparently forced from the degenerated synergid as pollen tube discharge occurs (11), but it is not clear whether it is of synergid or pollen tube origin, or both (Figure 2). The two male gametes quickly pass through the degenerate synergid and enter the intercellular space between the egg apparatus and the central cell plasma membranes (Figures 3, 9, 10, 11, 20, 26,27 ). The sperm cells at this time are typically associated with the previously mentioned osmiophilic material near the chalazal end of the egg (Figures 9, 10, 11, 26, 27). Each male gamete has a dense nucleus surrounded by a cytoplasmic sheath enclosed in a single plasma membrane. The sperm cytoplasm contains numerous organelles, most of which appear to be mitochondria, but some of which may be pro- plastids. Dictyosomes, ribosomes, endoplasmic reticulum, lipid bodies, and small vacuoles also occur (Figures 9, 10, 11, 26, 27, 31, 45, 46).

Fusion of egg and sperm. Upon entering the intercellular space between the egg apparatus and central cell, the plasma membrane of the male gamete apparently destined to fuse with the egg comes into intimate contact with the plasma membrane of the egg (Figure 11). Once in the egg cell, the male nucleus no longer has a cytoplasmic sheath of its own (Figure 12), and no examples have been seen where identifiable organelles of male origin were present within the egg cell cytoplasm. What appear to be male cytoplasmic sheaths have been observed just outside of the egg in the intercellular position where it would be expected that the male nucleus has entered (Figure 4). While travelling toward the egg nucleus, the male nucleus retains its previous dense appearance, and is aligned with its long axis parallel to the egg nucleus (Figures 4, 12). After reaching the egg nucleus, the male chromatin becomes progressively more diffuse as karyogamy takes place (Figures 13, 14, 15, 16). Nuclear fusion occurs by the formation of several bridges between the male and female nuclear membranes as has been described for other species $(16,25,34)$ (Figure 17). In one case, membranes of the endoplasmic reticulum were seen to fuse with both nuclear membranes (Figure 18). As nuclear fusion becomes complete, the male chromatin is still identifiable at one side of the zygote nucleus up to at least six hours post-pollination. Fragments of nuclear membranes are often seen within the zygote nucleus in the vicinity of the male chromatin, and by this time, new nucleoli are beginning to form in association with the male chromatin (Figure 19).

Triple fusion. A portion of the plasma membrane of the male gamete about to fuse with the central cell (as judged by its closer proximity to the polar nuclei as compared to the egg cell) comes in intimate contact with the central cell plasma membrane before entrance is effected (Figure 26). As in the case of the egg, after entrance of the male nucleus into the central cell, it no longer has its own cytoplasmic sheath, and no distinguishable male cytoplasmic components have been identified in the central cell cytoplasm. However, unlike the case of the egg, it has not 
been possible, so far, to identify any cytoplasmic sheaths that would be suspected of being left behind by the male gamete entering the central cell.

Upon reaching the partially fused polar nuclei, the male nucleus fuses with one polar nucleus in a manner similar to that described for the egg and sperm nuclei (Figures 21, 28). During the fusion process, the three nuclei migrate chalazally and become located near the antipodal cells (Figure 23). After entrance, the male chromatin quickly becomes diffuse and one or more new nucleoli begin to appear (Figures 22, 29, 30). Soon after fusion, the male chromatin is no longer distinguishable from that of the polar nucleus and the only evidence of fusion is the presence of extra nucleoli within the fusion nucleus (Figures 24, 25).

\subsection{Haploid embryo formation}

Chromosome counts made from squashes of developing embryo and endosperm tissues show that haploid embryos are always associated with normal, triploid endosperm. In four sectioned ovules ranging from 2 to $4 \frac{3 / 4}{4}$ hours post-pollination, it was found that the pollen tube had discharged into the degenerate synergid and that a normal, triple fusion condition was present in the central cell; yet, the egg had not been fertilized. In three of these ovules, no second male gamete was located; however, in the fourth ovule, which was fixed 4 to $43 / 4$ hours after pollination, a male gamete was found in the intercellular space between the egg apparatus and the central cell (Figure 31). The sperm cell consisted of a normal appearing nucleus with dense chromatin, and a typical cytoplasmic complement surrounded by a plasma membrane (Figure 32). The egg cell of this ovule contained a nucleus without male chromatin, and had normal cytoplasm with numerous mitochondria, plastids with starch grains, dictyosomes, lipid bodies, microbodies, endoplasmic reticulum and small vacuoles (Figures 31,33 ). In the central cell, the two partially fused polar nuclei had migrated to a position adjacent to the antipodals and one polar nucleus contained a typical large nucleolus plus a smaller, but sizeable, nucleolus such as would be expected by 4 hours after sperm entry (Figure 34). The other polar nucleus contained only a single, large nucleolus.
The pollen tube had entered this ovule by the expected route and discharged into the degenerate synergid (Figure 35 ).

\subsection{Embryoless caryopses}

Chromosome counts made from young ovules with developing cellular endosperm, but lacking an embryo, show that the endosperm of embryoless caryopses is triploid. In a sectioned ovule collected six hours after pollination, free-nucleate endosperm was present, yet there was no male chromatin in the egg nucleus; however, located in the chalazal intercellular space next to the egg, a sperm cell was found. The sperm chromatin was near normal in appearance, but lacked a nuclear envelope and the male cytoplasm was in an apparent degenerate state (Figures $36,37,38$ ). The egg cytoplasm of this ovule did not appear normal in that the plasma membrane was lacking and the plastid envelopes contained numerous, atypical, osmiophilic bodies (Figures 38, 39). Four examples of older ovules (i.e., collected 5 days after pollination and containing dividing cellular endosperm) showed only a small dense mass of cytoplasm in the micropylar position where a multicellular embryo would be expected (Figures 40, 41, 42, 43).

\subsection{Ovule abortion}

In three cases it was found that no polar nuclei were present in the embryo sac. In two of these ovules the egg had been fertilized normally, but the other male gamete was not found. In the third ovule, collected 2 to $23 / 4$ hours after pollination, the egg was unfertilized and a male gamete was located in the intercellular space just outside the egg (Figure 44). The sperm nucleus was of a typical dense appearance, and the cytoplasmic sheath, surrounded by an intact plasma membrane, was of normal make-up (Figure 45). The plasma membranes of the egg and sperm were in close association, while those of the central cell and sperm were separated by a distance of 0.06 $\mu \mathrm{m}$ to $0.29 \mu \mathrm{m}$ (Figures 45,46 ). In three additional examples, the egg had been fertilized, but, even though the polar nuclei were present, they were unfertilized. The other male gamete in these examples was not found. 


\section{DISCUSSION}

\subsection{Normal double fertilization}

Observations made during the present study on embryo sac structure and the process of double fertilization agree basically with those made on barley by Pope (24) and CASS and JeNSEN (4). However, the report by CASS (5) that "the male gametes leave the synergid entering a pocket of central cell cytoplasm" before effecting double fertilization was not confirmed by the present investigation; nor was an "intrusion of central cell cytoplasm into the degenerate synergid" (5) found to take place in the variety of Hordeum vulgare studied here.

Cass' (5) contention that the "male cytoplasm enters the egg as indicated by transmission of cytoplasmic virions by barley sperm cells (CARROLL and MAYHEW, 1976)" is not supported by the observations of this study, nor by the fact that mature male nuclei also contain viral particles (3). While the absence of a cytoplasmic sheath around the male nucleus and the lack of any identifiable male cytoplasmic organelles in the egg cytoplasm after syngamy (present study) do not dictate the interpretation that no male cytoplasm enters the egg, this information, along with the presence of what appears to be a male cytoplasmic sheath in the intercellular space just outside the egg at the point where the male nucleus entered, does offer preliminary support for such a conclusion. Additional observations on sperm entry into the egg, along with quantitative data from serial sections of the organelles within cytoplasmic sheaths outside the egg-zygote will be included in a subsequent report on fertilization in barley.

\subsection{Origin of haploid embryos}

Haploid embryos among angiosperms have been reported to arise in various ways in vivo: (1) Pollen tubes fail to reach some ovules of a given ovary, yet the egg cell is stimulated to develop into a haploid embryo (14). (2) The pollen tube enters the ovule, but does not discharge and the egg develops into a haploid embryo (14). (3) The male gamete enters the egg cytoplasm, but does not fuse with the egg nucleus; the egg goes on to form the embryo and the male chromatin either degenerates or becomes isolated from other parts of the embryo by cell wall formation $(17,27)$.
(4) Karyogamy occurs, but the male chromatin is subsequently eliminated during embryo development (28). (5) A synergid divides to form a haploid embryo $(8,9,20)$. (6) The male gamete gives rise to a haploid embryo $(7,12,18)$.

Observations made during the present investigation, along with those of M.D. BENNETT and R.A. FINCH of the Plant Breeding Institute, Cambridge, England, and W. Heneen, Department of Crop Genetics and Breeding, the Swedish University of Agricultural Sciences, Svalöv, who are studying the same barley mutant by the techniques of embryo sac dissection and paraffin embedded sections respectively, indicate that none of the above situations would explain the basis for haploidy in the plant under study. Since chromosome counts (present study; BENNETT and FINCH, unpublished, personal communication; HENEen, unpublished, personal communication) demonstrate that the endosperm associated with haploid embryos is triploid, triple fusion apparently occurs normally. This would indicate that the pollen tube does enter the embryo sac and that it discharges. Moreover, the finding by BENNETT and FINCH (unpublished, personal communication) and HENEEN (unpublished, personal communication) that the two-celled embryo is already haploid, contains no remnants of extra chromatin, and is associated with a persistent and degenerate synergid, offers convincing evidence that the haploid embryo arises from an unfertilized egg. The remaining question is: What happens to the other male gamete?

Four ovules of the present study showed normal triple fusion and eggs with no male chromatin. Since syngamy ordinarily occurs within one hour after pollination ( 24 ; present study) and these ovules were fixed from 2 hours to $43 / 4$ hours after pollination, it is concluded that the process of syngamy had failed in these ovules. This condition is exactly what might be expected to lead to haploid embryo formation; i.e., normal endosperm development and the formation of an embryo from the haploid egg. Although the second male gamete was not located in three of these ovules, in the fourth ovule an intact sperm cell was found in the intercellular space just outside the egg. Thus, it is concluded that caryopses containing haploid embryos arise as the result of normal triple fusion and the failure of the other male 
gamete to complete the final steps of its journey. At this point, it is assumed that entrance of the sperm into the egg is prevented by some physiological means since there appears to be no structural explanation of why this process is halted.

At first, it might be suspected that some deficiency exists on the male side; however, genetic studies show quite clearly that it is the genotype of the female parent which controls haploid embryo formation since the pollen source is not a factor (13; BodIL SøgAARD, unpublished, personal communication). A system such as this may prove to be useful for future studies on biochemical control mechanisms involved in syngamy within flowering plants.

\subsection{Embryoless caryopses}

Since chromosome counts (present study; BENNETT and FINCH, unpublished, personal communication) indicate that the endosperm of embryoless caryopses of the barley mutant under study is triploid, it appears that triple fusion occurs normally, but the embryo either is not formed in the first place, or if so, it aborts at an early stage. In one ovule of this study, which was fixed six hours after pollination, it was found that freenucleate endosperm was present, the egg was unfertilized, and the second male gamete was located in the intercellular space just outside the egg. This condition is reminiscent of that which is believed to result in caryopses with haploid embryos. However, in this particular case, even though the endosperm was developing normally, the egg cell was in a state of degeneration and, therefore, would likely have aborted, thus resulting in an embryoless caryopsis.

It appears, therefore, that embryoless caryopses are produced when, as in potential haploid embryo formation, triple fusion occurs, and the other male gamete reaches the intercellular space next to the egg, but does not move beyond this point. It may be that, in the case of embryoless caryopses, certain physiological conditions which might stimulate the egg to develop are not met and, thus, the egg degenerates while endosperm continues to develop. The presence of a male gamete just outside the egg, and developing endosperm do not appear to be sufficient stimuli, in themselves, to cause the egg to develop into a haploid embryo.

Other observations, from 5 day post-pollination ovules with cellular endosperm, lend support to the idea that if the embryo begins to develop at all, it does not get very far in potentially embryoless caryopses. In these ovules, only a small, dense mass of cytoplasm was found in the position where a multicellular, globular embryo normally would have developed by this time. This is just what would be expected if the entire egg apparatus had aborted at an early stage.

\subsection{Ovule abortion}

Ovule abortion in angiosperms has been reported to be associated with a variety of factors including the lack of fertilization $(1,22,26,32)$, failure of the embryo sac to complete its development $(2,6,19)$, high temperatures $(29,33)$, reduction of cell divisions in the nucellus (33), competition due to heavy crop load (10), suppression of other ovules in a given ovary by the first one to be fertilized (22), and blockage of the vascular trace leading to the ovule (23).

Several ovules of the present study provided evidence for the cytological basis of early ovule abortion. All of these cases involved the polar nuclei, which were either absent from the embryo sac, or if present, were unfertilized. Either of these conditions would result in the lack of endosperm formation and, consequently, eventual ovule abortion. In all but one of these examples the egg had been fertilized normally, yet the other male gamete was not found. These observations demonstrate that the two phases of double fertilization can occur independently from one another; i.e., even with or without the presence of polar nuclei, syngamy can occur normally. Likewise, the condition believed to result in haploid embryo formation demonstrates the autonomy of double fertilization events in that triple fusion can occur without syngamy.

In the case where the egg was not fertilized, a male gamete was located in the intercellular space just outside the egg. A close contact between the plasma membranes of the egg and sperm cell suggests that this male gamete had an affinity for the egg, yet actual entry was not accomplished. This condition is the same as that operating in haploid embryo formation and/or 
embryoless caryopsis formation, but in this case, the absence of polar nuclei could only lead to ultimate abortion of the entire ovule.

\section{ACKNOWLEDGEMENTS}

I would like to thank Professor Diter von WETTSTEIN for inviting me to undertake this project, for generously providing the facilities of the Department of Physiology, Carlsberg Laboratory, for helping with the hand-pollinations, and for critically reviewing the manuscript. Thanks are also extended to Bodil SøgaARd for providing the majority of the plants used in this investigation, to M.D. BENNETT and R.A. FINCH for valuable discussions, and to Waheeb Heneen, Professor Arne Hagberg, and Gunborg Hagberg for stimulating discussions and for providing a portion of the seed and some of the embedded material used in this study. Excellent technical assistance by Jean SAGE, ANN-Sofi Steinholtz, Kay LaBoone, Maxine Rusché, Peggy RossiTER and BIBI STAMPE ANDERSEN is gratefully acknowledged. Very special appreciation is extended to ShIRley Mogensen for outstanding technical assistance and untiring encouragement during this work. This study was supported in part by NSF grants PCM-8009020 and PRM8109097 , and by a grant from the Organized Research Fund, Northern Arizona University.

\section{REFERENCES}

1. BANERJI, l.: The development of the embryo sac and fertilization in jute. J. Indian Bot. Soc. 11, 228-240 (1932)

2. BHANDARi, N.N.: Studies in the family Ranunculaceae X. Embryology of Anemone L. Phytomorphology 18, 487-497 (1968)

3. Carroll, ,T.W. \& D.E. MaYhew: Anther and pollen infection in relation to the pollen and seed transmissibility of two strains of barley stripe mosaic virus in barley. Can. J. Bot. 54, 1604-1621 (1976)

4. Cass, D.D. \& W.A. Jensen: Fertilization in barley. Amer. J. Bot. 57, 62-70 (1970)

5. CASs, D.D.: Structural relationships among central cell and egg apparatus cells of barley as related to transmission of male gametes. Acta Soc. Bot. Pol. 50, 177-180 (1981)

6. Catalono, G.: Contributo alla conoscenza della cause della sterilita in Agave e Fourcroya. Lav. 1st Bot. Palermo 1, 1-60 (1930)
7. Clausen, R.E. \& W.E. Lammerts: Interspecific hybridization in Nicotiana. X. Haploid and diploid merogony. Amer. Nat. 63, 279-322 (1929)

8. COOPER, D.C.: Haploid-diploid twin embryos in Lilium and Nicotiana. Amer. J. Bot. 30, 408-413 (1943)

9. CRETÉ, P.: Un cas de polyembryonie chez une Gentianacee, l'Erythraea centaurium. Pers. Bull. Soc. Bot. de France 96, 113-115 (1949)

10. DoRSEY, J.M.: A study of sterility in the plum. Genetics 4, 417-488 (1919)

11. Fisher, D.B. \& W.A. Jensen: Cotton embryogenesis: The identification, as nuclei, of the $\mathrm{X}$-bodies in the degenerate synergid. Planta 84 , 122- 133 (1969)

12. Gerassimova, H.: Experimentell erhaltene haploide Pflanze von Crepis teciorum L. Planta 25, 696-702 (1936)

13. Hagberg, A. \& G. Hagberg: High frequency of spotaneous haploids in the progeny of an induced mutation in barley. Hereditas 93, 341343 (1980)

14. Hagerup, O.: Facultative parthenogenesis and haploidy in Epipactis latifolia. K. Danske Vidensk. Selskab., Biol. Meddel. 19, 1-13 (1945)

15. Jensen, C.J.: Monoploid production in barley: Advances through in vitro culture. In: Applied and fundamental aspects of plant tissue and organ culture. J. Reinert \& Y.P.S. Bajaj, eds., Springer-Verlag, New York (1977)

16. Jensen, W.A. \& D.B. Fisher: Cotton embryogenesis: Double fertilization. Phytomorphology 17, 261-269 (1967)

17. JøRgensen, C.A.: The experimental formation of heteroploid plants in the genus Solanum. J. Genet. 19, 133-211 (1928)

18. Kostoff, D.: An androgenic Nicotiana haploid. Ztschr. f. Zellforsch. u. Mikros. Anat. 9, 640642 (1929)

19. LANGDON, L.M.: Ontogenetic and anatomical studies of the flower and fruit of the Fagaceae and Juglandaceae. Bot. Gaz. 101, 301-327 (1939)

20. Lebégue, A.: Embryologie des Saxifragacées. Polyembryonie chez le Bergenia delavayi. Engl. Bull. Soc. Bot. de France 96, 38-39 (1949)

21. Mogensen, H.L.: A modified method for reembedding thick epoxy sections for ultramicrotomy. J. Arizona Acad. Sci. 6, 249-250 (1971)

22. Mogensen, H.L.: Ovule abortion in Quercus (Fagaceae). Amer. J. Bot. 62, 160-165 (1975)

23. Pimienta, E. \& V.S. Polito: Ovule abortion in "Nonpariel" almond (Prunus dulcis (Mill.) D.A. Webb). Amer. J. Bot. 69, 913-920 (1982) 
24. POPE, M.: The time factor in pollen-tube growth and fertilization in barley. J. Agr. Res. 54, 525529 (1937)

25. RusSelL, S.D. \& D.D. Cass: Ultrastructure of fertilization in Plumbago zeylanica. Acta Soc. Bot. Pol. 51, 185-190 (1981)

26. SaChar, R.C. \& K. KANTA: Influence of growth substances on artificially cultured ovaries of Tropaeolum majus L. Phytomorphology 8, 202218 (1958)

27. Solntzeva, M.: Apomixis and hemigamy as one of its forms. Proc. Indian Natn. Sci. Acad. B44, 78-90 (1978)

28. Subrahmanyam, N.C. \& K.J. Kasha: Selective chromosome elimination during haploid formation in barley following interspecific hybridization. Chromosoma 42, 111-125 (1973)

29. Thompson, M.M. \& L.J. Liv: Temperature, fruit set and embryo sac development in "Italian” prune. J. Amer. Soc. Hort. Sci. 98, 193-197 (1973)

30. Tilton, V.R.: The female reproductive system in Ornithogalum caudatum. Ph.D. Dissertation. Iowa State University, Ames, Iowa (1978)

31. Van der Woude, W.J., D.J. Morré \& C.E. BRACKER: Isolation and characterization of secretory vesicles in germinated pollen of Lilium longiflorum. J. Cell Sci. 8, 331-351 (1971)

32. WALKER, R.I.: Megasporogenesis and embryo development in Tropaeolum majus L. Bull. Torrey Bot. Club. 74, 240-249 (1947)

33. WILLIAMS, R.R.: The effect of summer nitrogen applications on the quality of apple blossoms. J. Hort. Sci. 40, 31-41 (1965)

34. WILMS, H.J.: Pollen tube penetration and fertilization in spinach. Acta Bot. Neerl. 30, 101-122 (1981)

Figure 1. Median longisection through the mature embryo sac before pollination showing two synergids $(\mathrm{S})$, polar nuclei ( $\mathrm{Po}$ ), and the antipodals ( $\mathrm{A}$ ) at the chalazal end of the central cell. Section stained with basic fuchsin and methylene blue. $175 \mathrm{X}$.

Figure 2. Median longisection through the micropylar end of an ovule fixed 2 to $2 \frac{3}{4}$ hours after pollination showing the pollen tube (T) between the inner integument (II) and the inner epidermis of the carpel (C), within the micropyle of the inner integument, between nucellar cells (N) and in the degenerate synergid (DS). Note that osmiophilic material (unlabelled arrow) has emerged from the degenerate synergid and is located in the intercellular space around the chalazal end of the egg $(E) . \mathrm{OI}=$ outer integument. Section unstained. $310 \mathrm{X}$.

Figure 3. Partial transverse section through the egg apparatus of an ovule fixed 1 to $13 / 4$ hours after pollination. The sperm cell (SP) has emerged from the degenerate synergid (DS) and is located in the intercellular space between the egg (E) and central cell (CC). PS = persistent synergid. Section unstained. 1,200X.

Figure 4. Near transverse section of an egg fixed 1 to $1^{3 / 4}$ hours after pollination. The sperm nucleus (unlabelled arrow) is located just outside the egg (E) nucleus (Nu). Note cytoplasmic sheath (Cy) in the intercellular space just outside the egg. Section unstained. 1,200X.

Figure 5. Longisection through the micropylar end of an ovule fixed 4 to $4 \frac{3}{4}$ hours after pollination showing pollen tubes (T) outside the inner integument (II), in the micropyle and nucellus (N) and in the degenerate synergid (DS). Note male chromatin (unlabelled arrow) within the egg (E) nucleus. $\mathrm{C}=$ carpel. 1,400X.

Figure 6. Pollen tube (T) near the micropylar end of an ovule fixed 2 to $23 / 4$ hours after pollination. Note degenerate condition of pollen tube cytoplasm. $\mathrm{C}=$ carpel; $\mathbf{I I}=$ inner integument; $\mathrm{M}=$ mitochondrion. $11,700 \mathrm{X}$.

Figure 7. Portions of two pollen tubes $(\mathrm{T})$ in the micropyle of an ovule fixed 2 to $23 / 4$ hours after pollination. Unlabelled arrows = polysaccharide spheres; $\mathrm{C}=$ carpel; $\mathrm{II}=$ inner integument; $\mathrm{N}=$ nucellus. $11,700 \mathrm{X}$.

Figure 8. Pollen tube tip ( $T$ ) within the filiform apparatus (FA) of the degenerate synergid (DS). The presence of polysaccharide spheres (unlabelled arrows) within the degenerate synergid demonstrate that the pollen tube has discharged even though the pore does not show in this level of section. $\mathbf{N}=$ nucellus; PS = persistent synergid; $\mathbf{S T}=$ starch grain. 14,300X. 
Figure 9. Sperm cell (SP) in the intercellular space between the egg (E) and central cell (CC). Taken from the same section as shown in Figure 3 . DS $=$ degenerate synergid; $L=$ lipid body in sperm cytoplasm; $M=$ mitochondria in sperm cytoplasm; $\mathrm{Nu}=$ sperm nucleus; $\mathrm{OM}=$ osmiophilic material in intercellular space; $\mathrm{V}=$ sperm vacuole. $23,400 \mathrm{X}$

Figure 10. Serial section from same ovule as Figure 9 showing a more median view and higher magnification of sperm cell (SP) within the intercellular space. Note distinct sperm plasma membrane at unlabelled arrow. $\mathrm{CC}=$ central cell; $\mathrm{DS}=$ degenerate synergid; $\mathrm{E}=\mathrm{egg}, \mathrm{Nu}=$ sperm nucleus; $\mathrm{OM}=$ osmiophilic material; $\mathrm{V}=$ sperm vacuole. $31,200 \mathrm{X}$.

Figure 11. Serial section from same ovule as in Figures 9 and 10 showing higher magnification of contact between plasma membranes of egg (E) and sperm (SP). $\mathrm{M}=$ mitochondria in egg; $\mathrm{Nu}=$ sperm nucleus; $\mathrm{OM}=$ osmiophilic material; $P$ = probable proplastid. $31,200 \mathrm{X}$.

Figure 12. Sperm nucleus (SN) within egg cytoplasm near egg nucleus (EN). From same section as shown in Figure 4. $19,500 X$.

Figure 13. Egg apparatus from an ovule fixed 1 to $1 \frac{3 / 4}{4}$ hours after pollination showing the male nucleus (unlabelled arrow) fusing with the egg nucleus $(\mathrm{Nu}) . \mathrm{E}=$ egg; $\mathrm{PS}=$ persistent synergid. Section unstained. 1,200X.

Figure 14. Egg apparatus from an ovule fixed 2 to $23 / 4$ hours after pollination showing the sperm nucleus (unlabelled arrow) fusing with the egg nucleus $(\mathrm{Nu})$. $\mathrm{DS}=$ degenerate synergid; $\mathrm{E}=$ egg. Section unstained. $1,200 \mathrm{X}$.

Figure 15. Egg from an ovule fixed 2 to $23 / 4$ hours after pollination showing sperm nucleus (unlabelled arrow) fusing with the egg nucleus $(\mathrm{Nu})$. Note the less-dense nature of the male chromatin compared to Figures 13 and $14 . \mathrm{E}=$ egg. Section unstained. $1,200 \mathrm{X}$.

Figure 16. Egg apparatus from an ovule fixed 4 to $4 \frac{3 / 4}{4}$ hours after pollination showing diffuse male chromatin (unlabelled arrow) within the egg nucleus $(\mathrm{Nu}) . \mathrm{DS}=$ degenerate synergid; PS = persistent synergid. Section unstained. $1,200 \mathrm{X}$.

Figure 17. Sperm nucleus (SN) fusing with egg nucleus (EN). From same section as shown in Figure 14. ER = endoplasmic reticulum. 31,200X.

Figure 18. Serial section from same ovule as in Figure 17 showing fusion of endoplasmic reticulum with both the egg nuclear membrane and the sperm nuclear membrane. Note fusion of outer nuclear membranes of egg nucleus (EN) and sperm nucleus (SN) at unlabelled arrows. 39,000X.

Figure 19. Later stages of karyogamy from an ovule fixed 4 to $43 / 4$ hours after pollination. Note newly formed male nucleolus (Nus) and remnants of nuclear membranes from egg nucleus (EN) and sperm nucleus (SN) at unlabelled arrows. $P=$ plastid; $\mathrm{ST}=$ starch grain. $15,600 \mathrm{X}$

Figure 20. Partial transverse section through the micropylar end of the same ovule as shown in Figure 3. A sperm cell $(\mathrm{SP})$ is in the intercellular space next to the polar nuclei $(\mathrm{Po}) . \mathrm{CC}=$ central cell; Nus = nucleolus. Section unstained. $1,200 \mathrm{X}$.

Figure 21. Sperm nucleus (SN) fusing with one of the polar nuclei (Po) in an ovule fixed 2 to $23 / 4$ hours after pollination. Nus $=$ nucleolus. Section unstained. 1,200X.

Figure 22. Sperm chromatin (SC) within a polar nucleus (Po) at 1 to $13 / 4$ hours after pollination. Nus = nucleolus. Section unstained. $1,200 \mathrm{X}$.

Figure 23. Serial section from same polar nuclei (Po) as in Figure 22 showing two large nucleoli (Nus), one in each polar nucleus. $A=$ antipodals. Stained with basic fuchsin and methylene blue. 1,200X. 
Figure 24. Two polar nuclei (Po) each with a single large nucleolus (Nus) at 4 to $43 / 4$ hours after pollination. 1,200X.

Figure 25. Serial section from same polar nuclei ( $\mathrm{Po}$ ) as in Figure 24 showing absence of distinct male chromatin and presence of a smaller nucleolus (unlabelled arrow) within the polar nucleus which has fused with the sperm nucleus. $1,200 \mathrm{X}$.

Figure 26. Sperm cell (SP) within the intercellular space next to the polar nuclei. Taken from the same section as shown in Figure 20. Note that plasma membranes of sperm and central cell (CC) come in intimate contact (unlabelled arrows). $\mathrm{DS}=$ degenerate synergid; $\mathrm{OM}=$ osmiophilic material; $\mathrm{Nu}=$ sperm nucleus. $19,500 \mathrm{X}$.

Figure 27. Same section as in Figure 26 showing polar nuclei (Po) and numerous organelles in the central cell (CC) cytoplasm. DS = degenerate synergid; $\mathrm{OM}=$ osmiophilic material; $\mathrm{SN}=$ sperm nucleus; $\mathrm{Nus}=$ nucleolus. $19,500 X$.

Figure 28. Sperm nucleus (SN) fusing with polar nucleus ( $\mathrm{Po}$ ). From an ovule fixed 2 to $2 \frac{3 / 4}{4}$ hours after pollination. Nus $=$ nucleolus; $\mathrm{CC}=$ central cell. $19,500 \mathrm{X}$.

Figure 29. Partially fused polar nuclei (Po) with sperm chromatin (SC) in one polar nucleus. From same section as shown in Figure 22. Nus = nucleolus. 10,000X.

Figure 30. Higher magnification of same sperm chromatin (SC) as in Figure 29, showing male nucleolus (Nus) beginning to form and a portion of nuclear membrane (unlabelled arrows; note nuclear pores) nearby demonstrating karyogamy was recently completed. $\mathrm{CC}=$ central cell; $\mathrm{Po}=$ polar nucleus. $19,500 \mathrm{X}$.

Figure 31. Chalazal end of an egg apparatus from an ovule fixed 4 to $43 / 4$ hours after pollination, showing a sperm cell (SP) within the intercellular space just outside the egg (E). $\mathrm{CC}=$ central cell; $\mathrm{Nu}=$ sperm nucleus; $\mathrm{OM}=$ osmiophilic material; $\mathrm{PS}=$ persistent synergid; $\mathrm{ST}=$ starch grain within a plastid. 19,500X .

Figure 32. Higher magnification of same section as in Figure 31, showing details of the intercellular sperm cell (SP). $\mathrm{CC}=$ central cell; $\mathrm{E}=$ egg; $\mathrm{Nu}=$ sperm nucleus; $\mathrm{OM}=$ osmiophilic material; $\mathrm{PS}=$ persistent synergid. $31,200 \mathrm{X}$.

Figure 33. Egg nucleus and associated cytoplasm from same ovule as in Figure 31. ER = endoplasmic reticulum; $\mathrm{L}$ $=$ lipid body; $\mathbf{M}=$ mitochondria; $\mathrm{Mi}=$ microbody; Nus = nucleolus; $\mathrm{ST}=$ starch grain in plastid. $19,500 \mathrm{X}$.

Figure 34. Partially fused polar nuclei (Po) showing one nucleus with a typical, large nucleolus (Nus) and another sizeable, but smaller nucleolus (Nus) presumably of male origin. Second polar nucleus contained only a single, large nucleolus (not visible at this level of sectioning). $\mathrm{CC}=$ central cell. $11,700 \mathrm{X}$.

Figure 35. Micropylar end of same ovule as in Figures 31, 32, 33, and 34 showing the pollen tube (T) within the filiform apparatus (FA) of the degenerate synergid (DS). PS = persistent synergid. 19,500X.

Figure 36. Transverse section through the micropylar end of an ovule fixed 6 hours after pollination, showing a sperm cell (SP) in the intercellular space near the chalazal end of the egg (E). Section unstained. 1,200X.

Figure 37. Same ovule as in Figure 36 cut at a deeper level to show the egg (E) nucleus. $\mathrm{Nu}$. Section unstained. $1,200 \mathrm{X}$.

Figure 38. Sperm cell (SP) within the intercellular space just outside the egg (E) showing the sperm nucleus (Nu) and degenerate sperm cytoplasm. Note lack of egg plasma membrane. Taken from same section as in Figure 36. CC = central cell; $\mathrm{OM}=$ osmiophilic material in intercellular space. $19,500 \mathrm{X}$.

Figure 39. Transverse section through the unfertilized egg at the level of the nucleus ( $\mathrm{Nu}$ ) showing the peculiar osmiophilic globules associated with the plastid (P) membranes (unlabelled arrows). Note lack of tonoplast around many of the vacuoles (V). Taken from same section as shown in Figure 37. ST = starch grain. 19,500X. 
Figure 40. Cellular endosperm (EN) within an ovule fixed 5 days after pollination. Note mitotic figure indicating that the endosperm was dividing and apparently developing normally. Section unstained. 800X.

Figure 41. Micropylar end of same ovule as shown in Figure 40 showing degenerate cytoplasm (DC) and what appears to be a collapsed egg (E). Section unstained. II = inner integument; $N=$ nucellus. $800 \mathrm{X}$.

Figure 42. Micropylar end of an ovule fixed 5 days after pollination showing dividing (unlabelled arrow) endosperm (EN) and degenerate cytoplasm (DC) in the position where a multicellular embryo would be expected by this time (such as shown in Figure 43). Section unstained. 800X.

Figure 43. Micropylar end of an ovule fixed 5 days after pollination showing a multicellular embryo (EM) with mitotic figures (unlabelled arrow). $\mathrm{EN}=$ endosperm. Section unstained. $800 \mathrm{X}$.

Figure 44. Longisection through the egg (E) of an ovule fixed 2 to $2^{3 / 4}$ hours after pollination showing a sperm cell $(\mathrm{SP})$ in the intercellular space just outside the egg. Section unstained. $1,200 \mathrm{X}$.

Figure 45. Electron micrograph of an ultrathin section taken from the same section as shown in Figure 44 showing details of the sperm cell (SP) within the intercellular space between the egg (E) and the central cell (CC). Note closer contact between egg and sperm plasma membranes compared to those of the sperm and central cell. $\mathrm{Nu}=$ nucleus; $\mathrm{OM}=$ osmiophilic material; $\mathrm{P}=$ probable proplastid; $\mathrm{V}=$ vacuole. $15,600 \mathrm{X}$.

Figure 46. Higher magnification of same section as shown in Figure 45 showing further details of the sperm (SP) cytoplasm and close association between the egg $(\mathrm{E})$ and sperm plasma membranes (arrows). $\mathrm{CC}=$ central cell; $\mathrm{D}=$ dictyosome; $\mathrm{L}=$ lipid body; $\mathrm{Nu}=$ nucleus; $\mathrm{OM}=$ osmiophilic material. $31,200 \mathrm{X}$. 


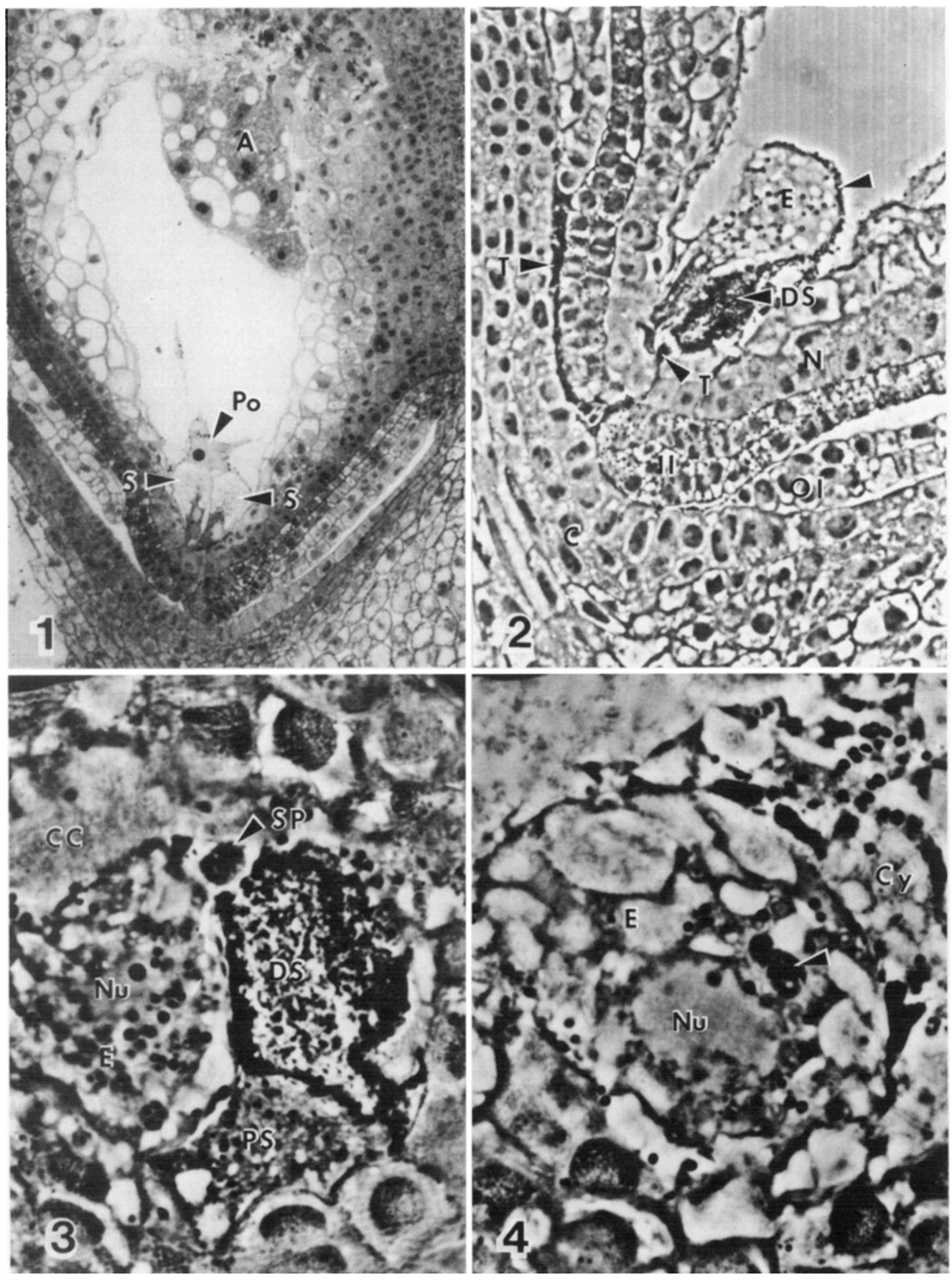




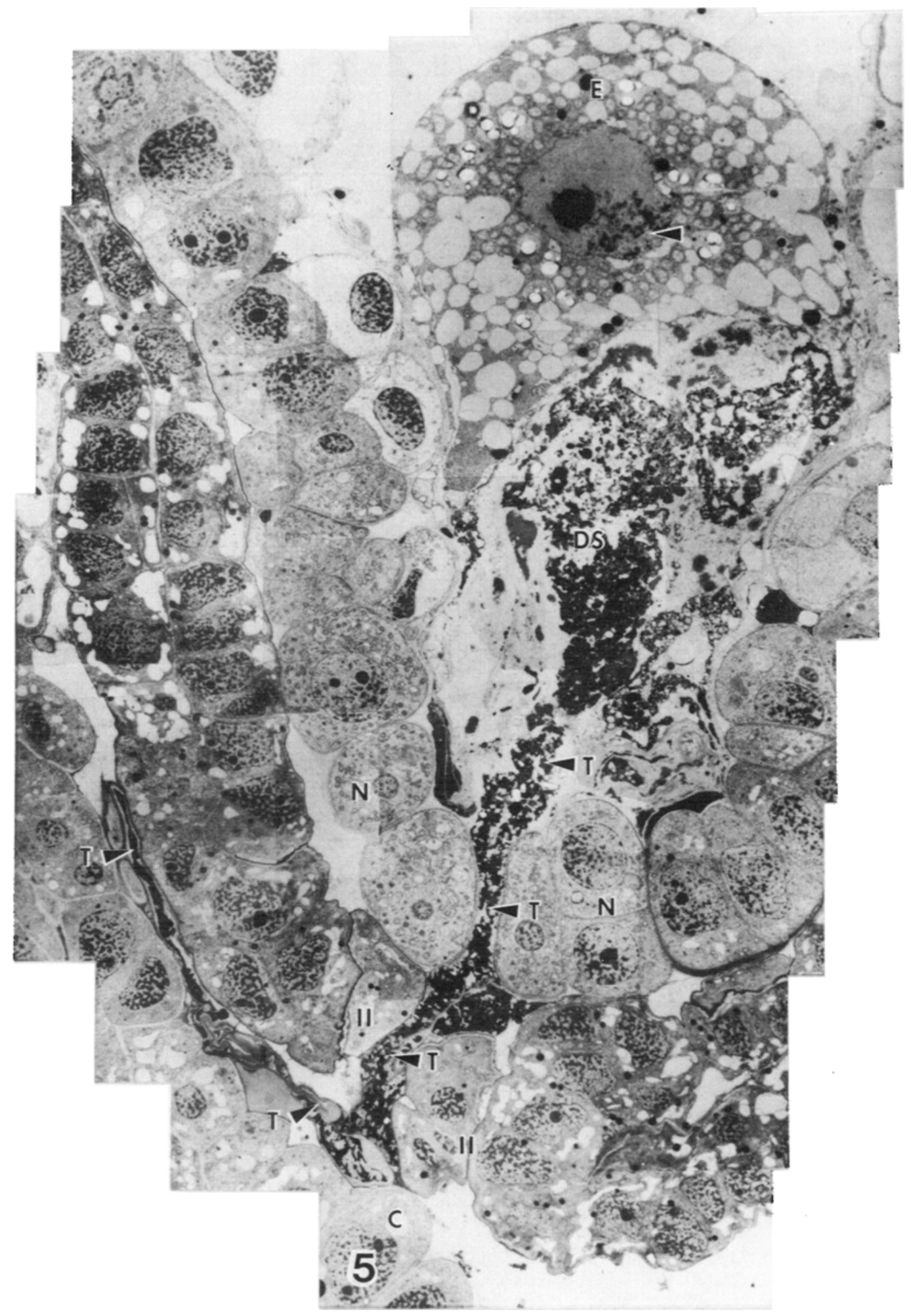




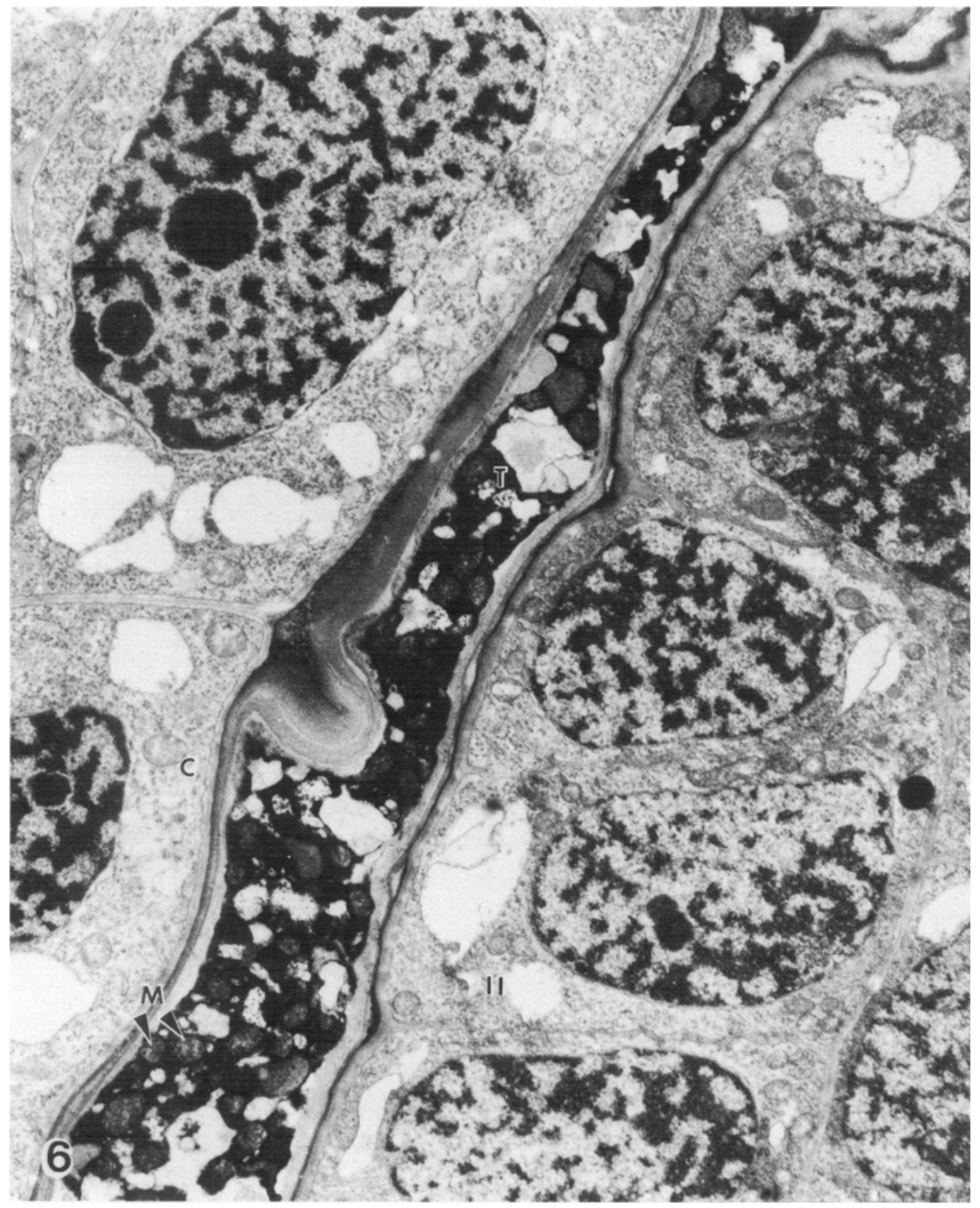




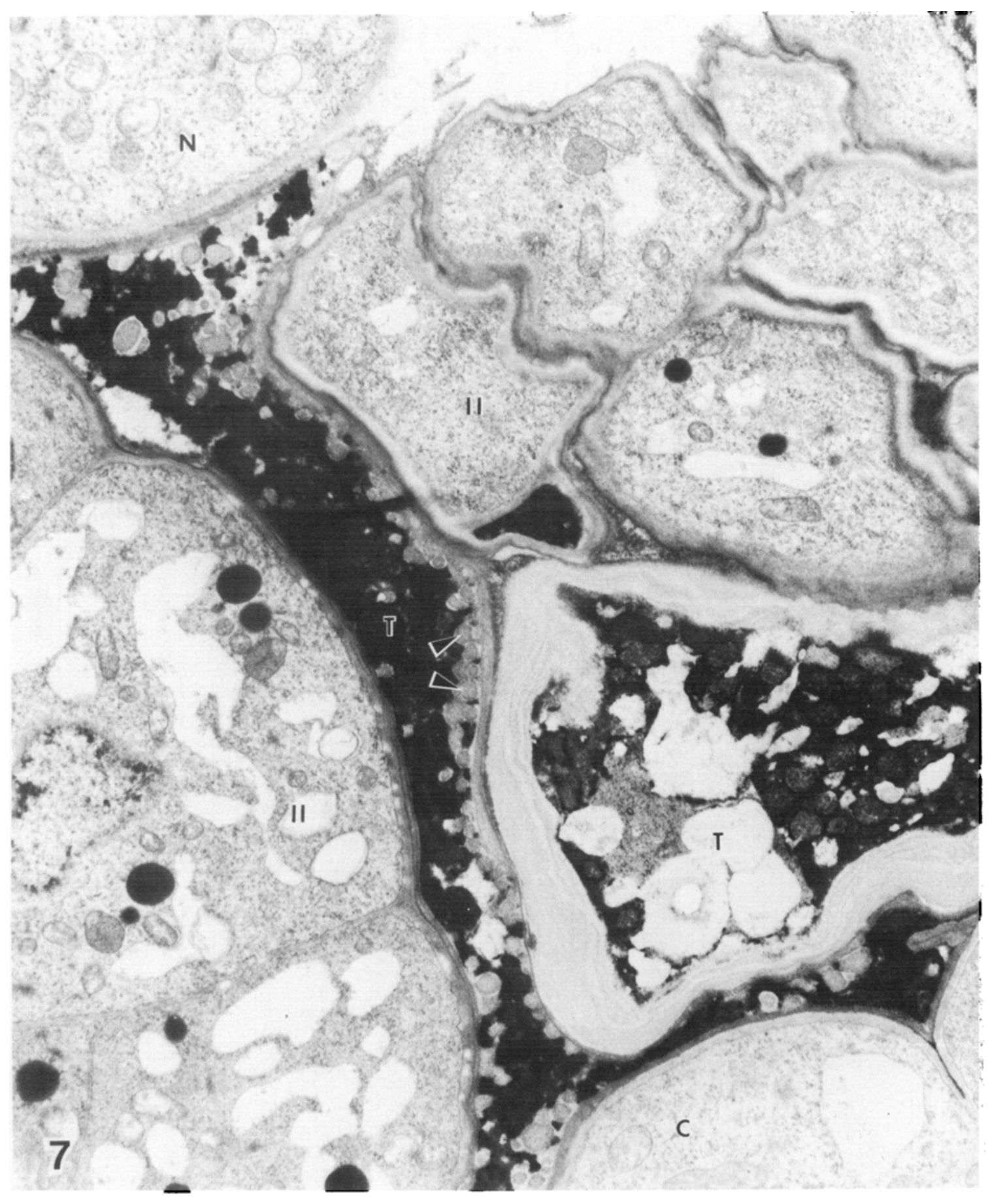




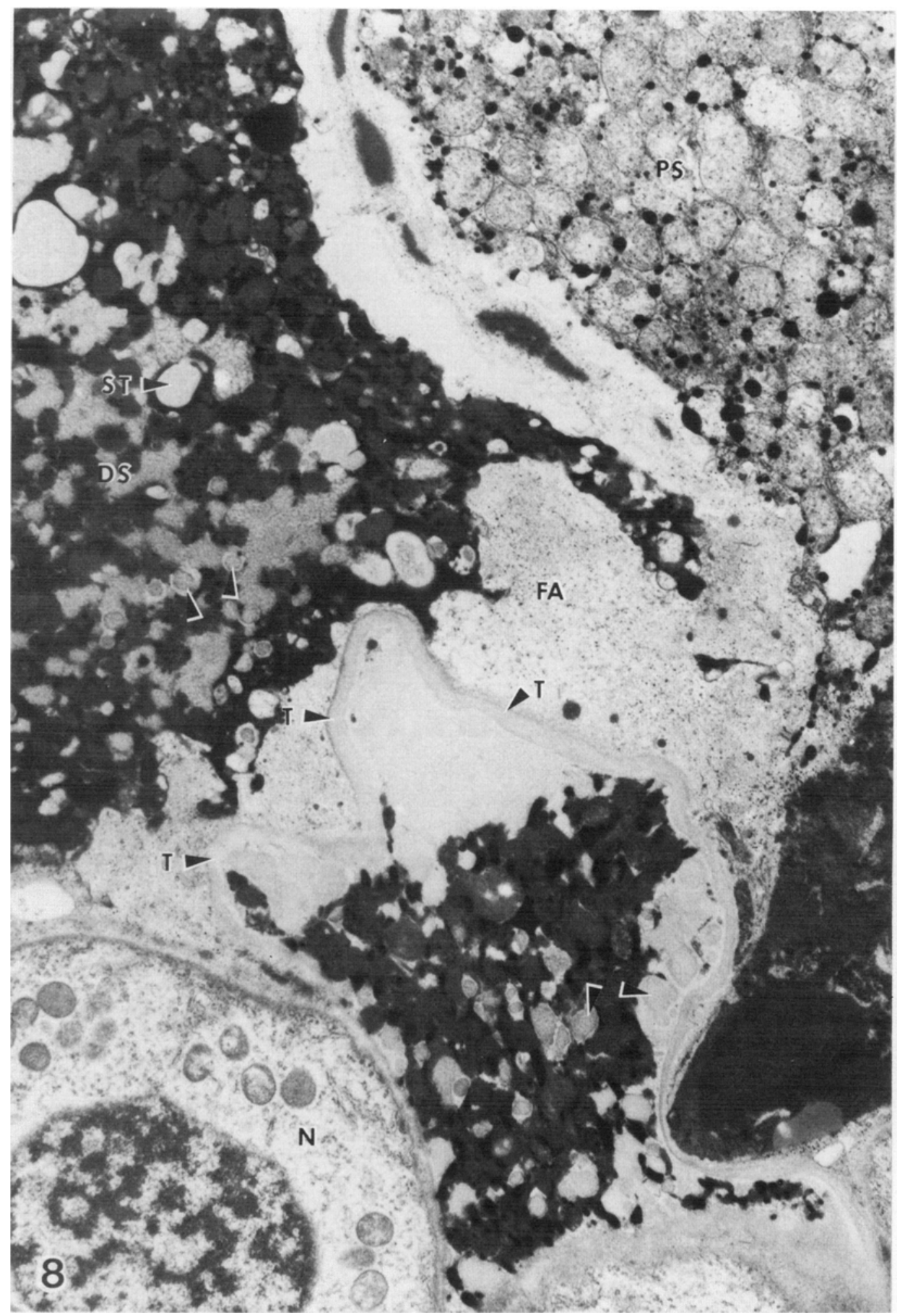




\section{H. Lloyd Mogensen: Double fertilization in barley}

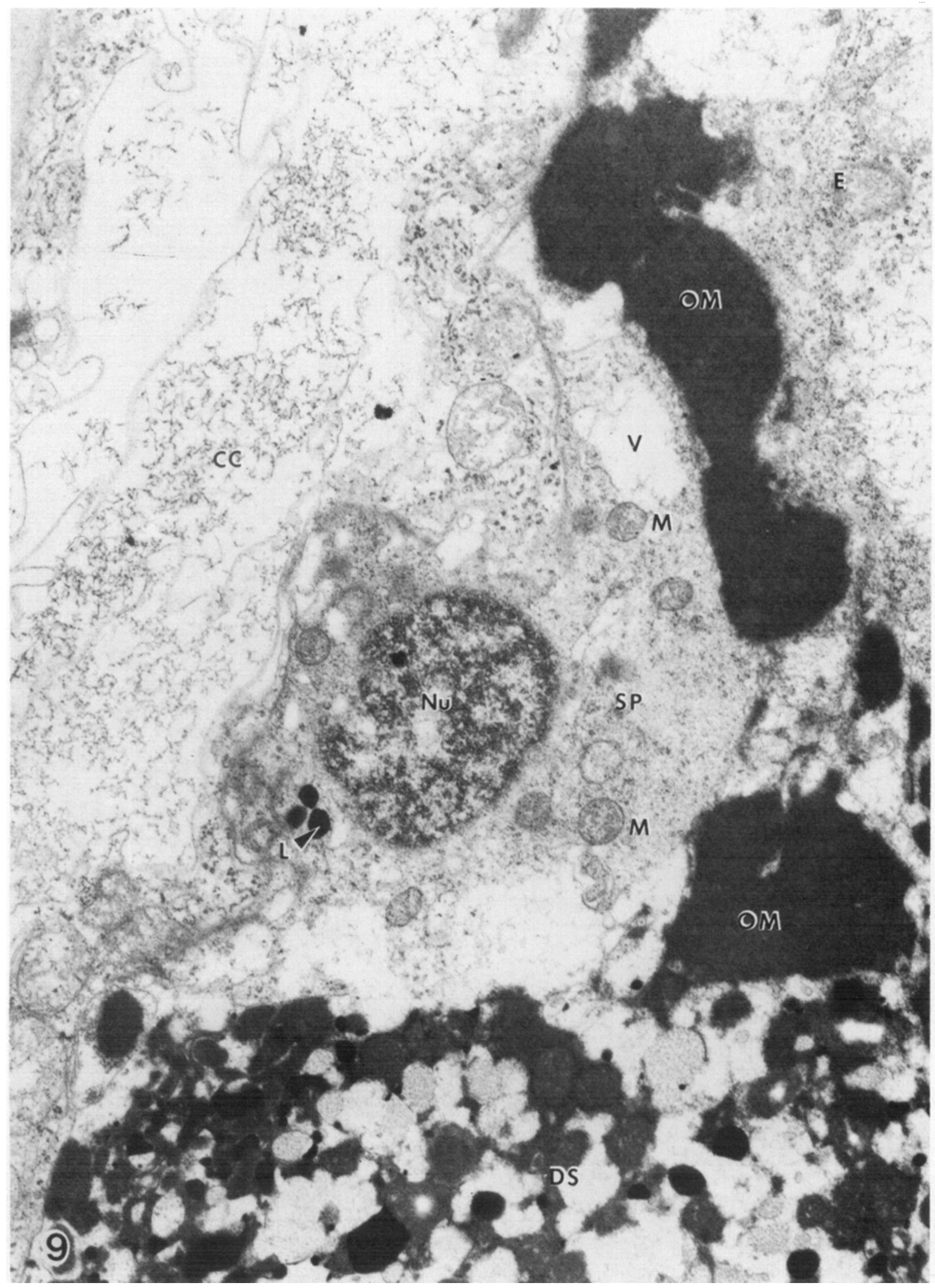




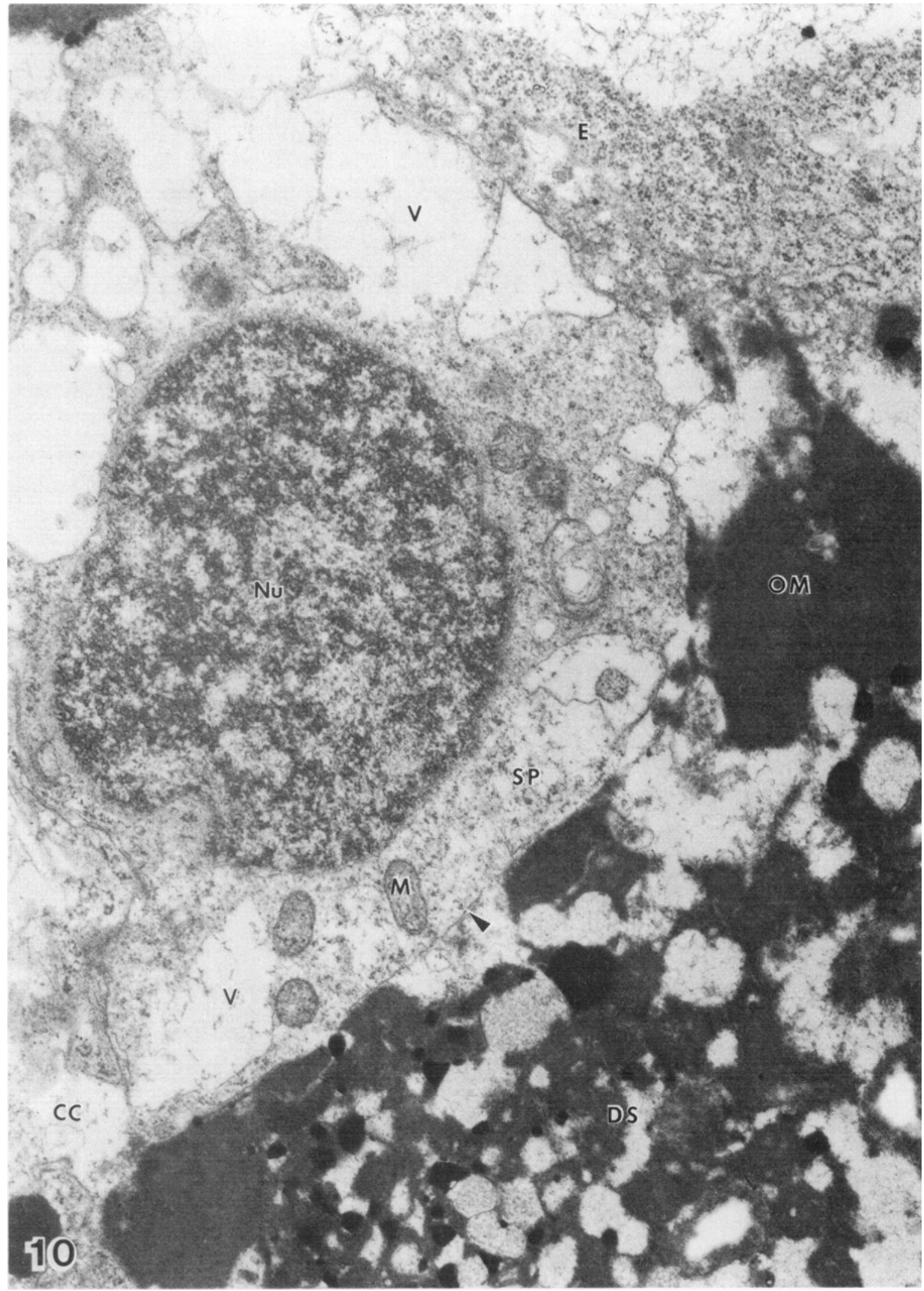




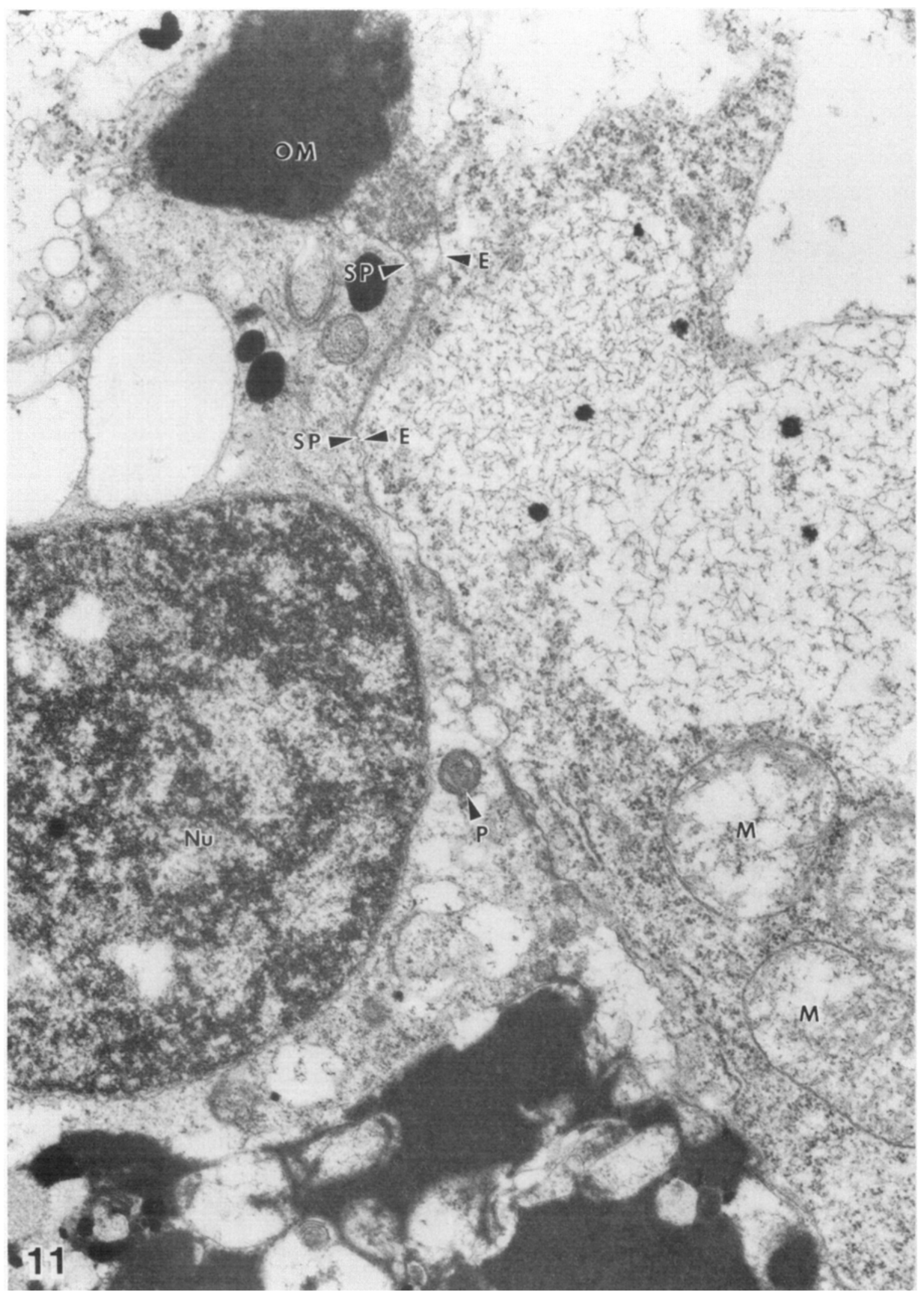




\section{H. Lloyd Mogensen: Double fertilization in barley}

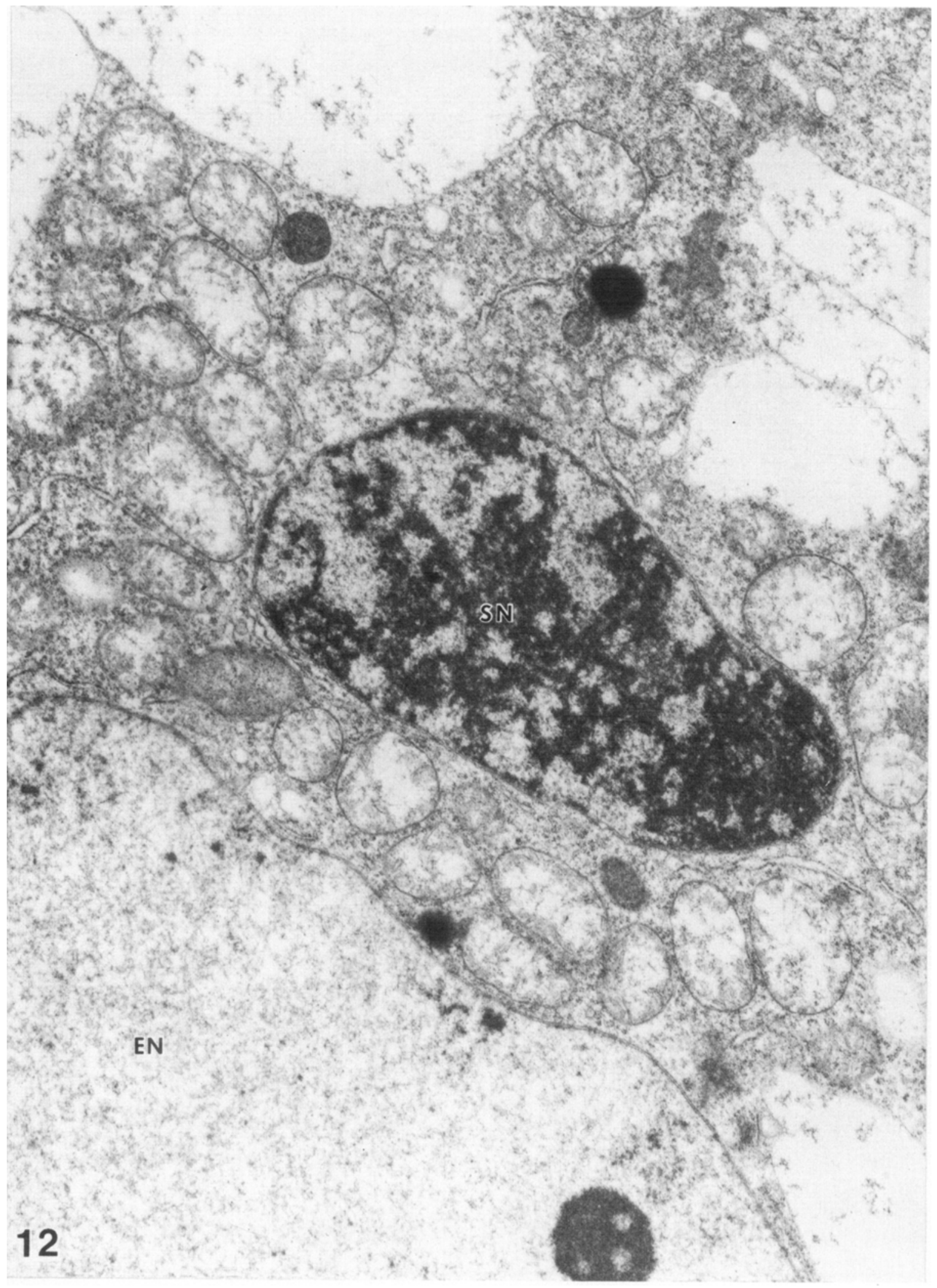




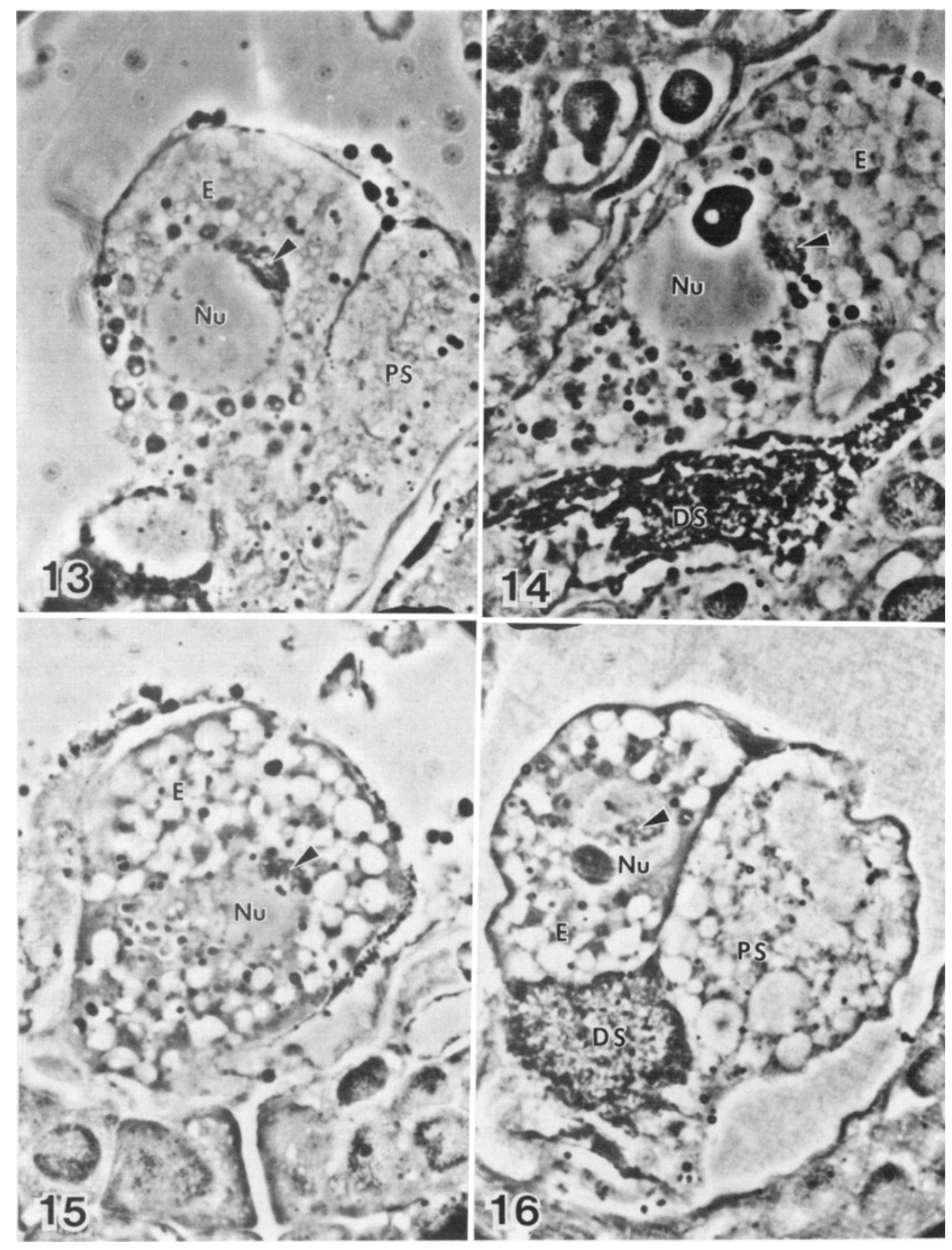




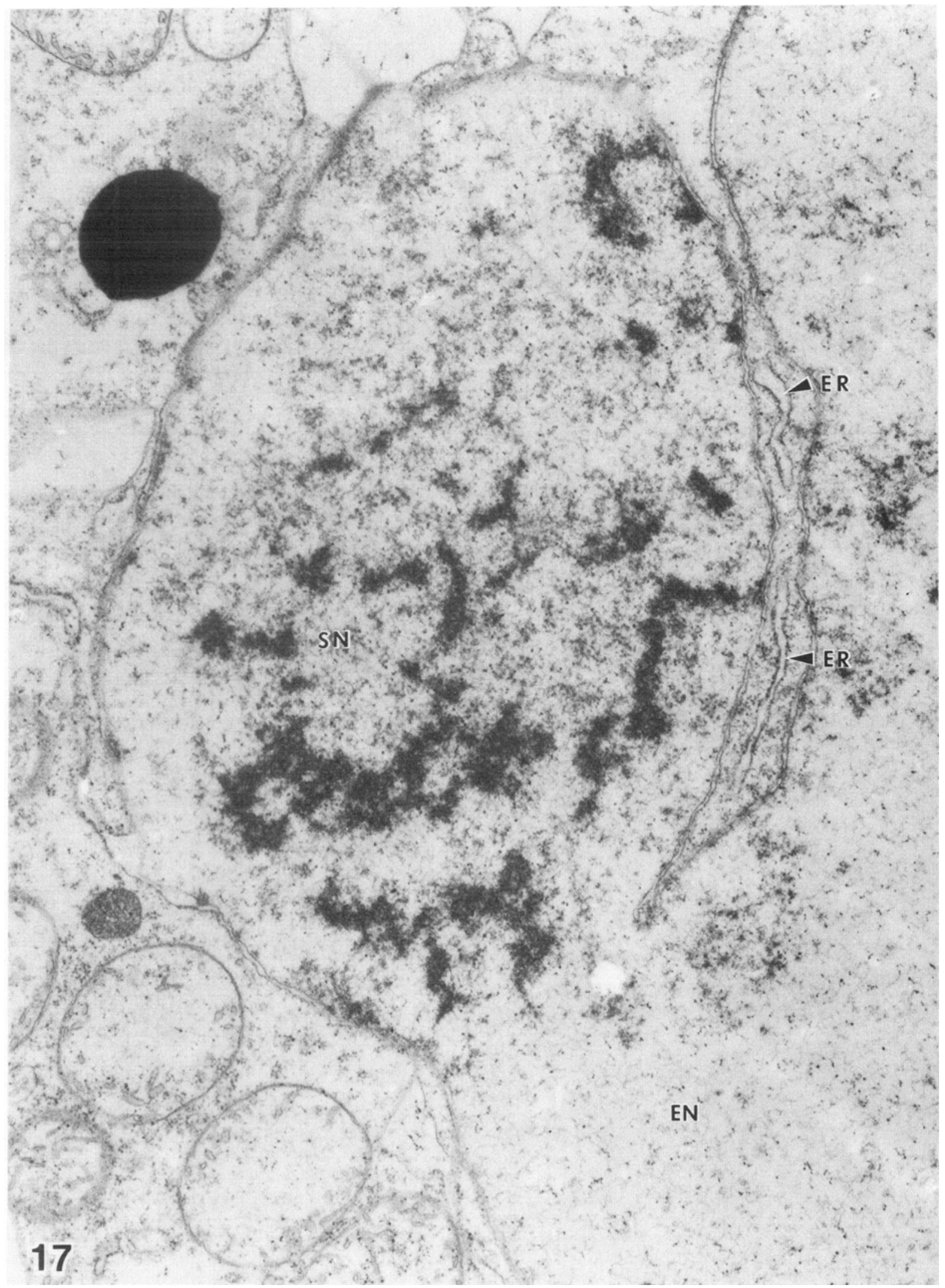


H. Lloyd Mogensen: Double fertilization in barley

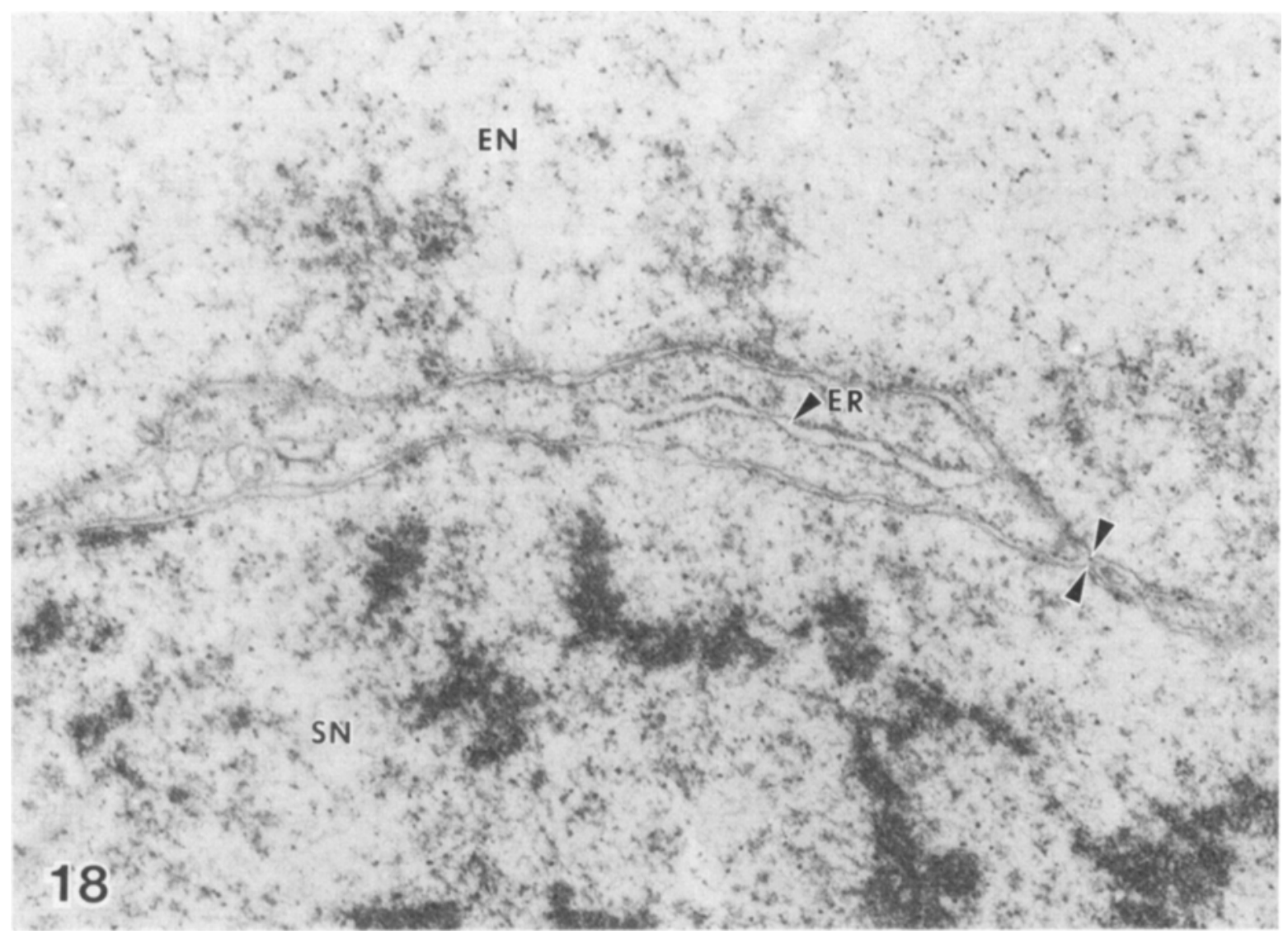




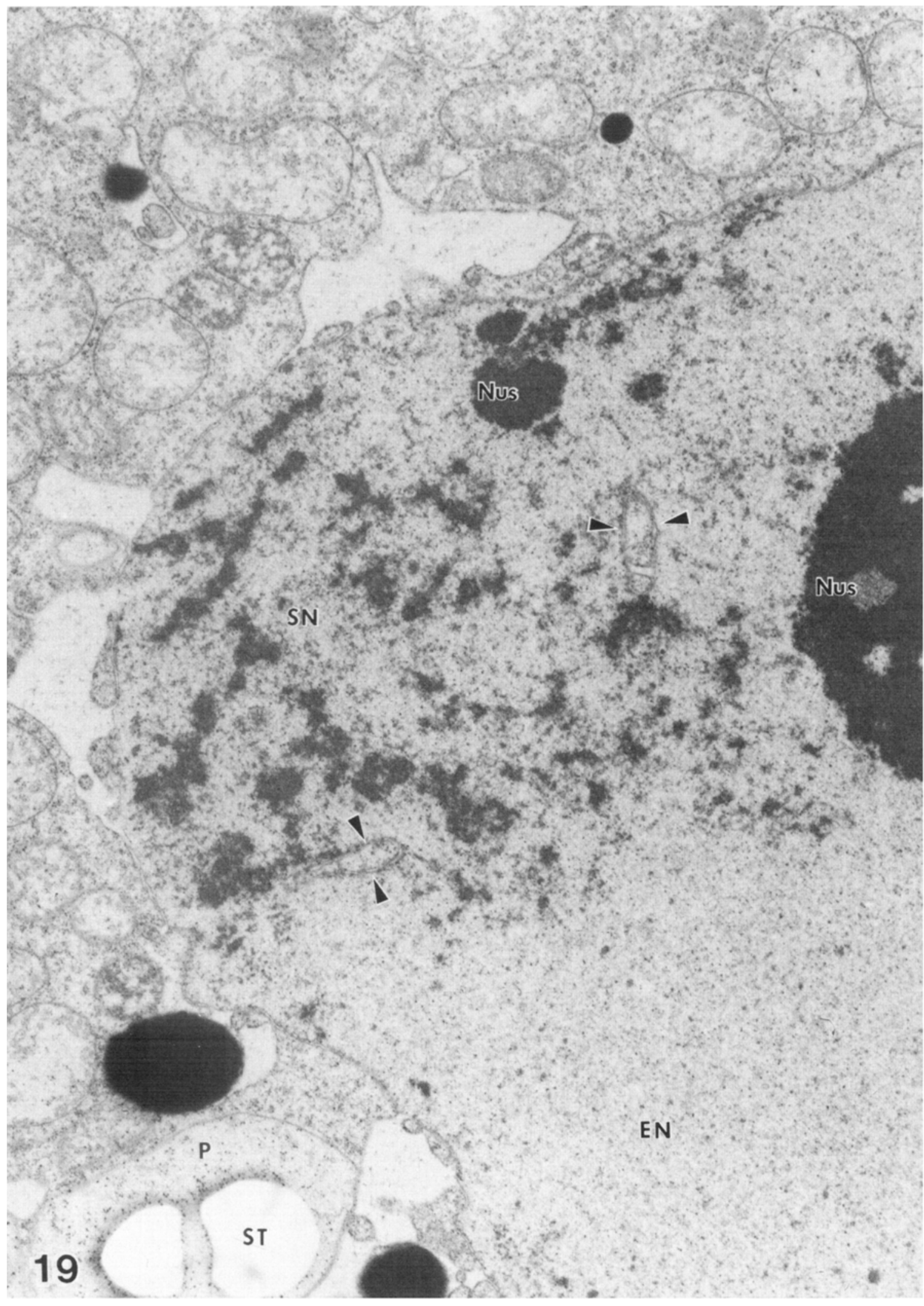




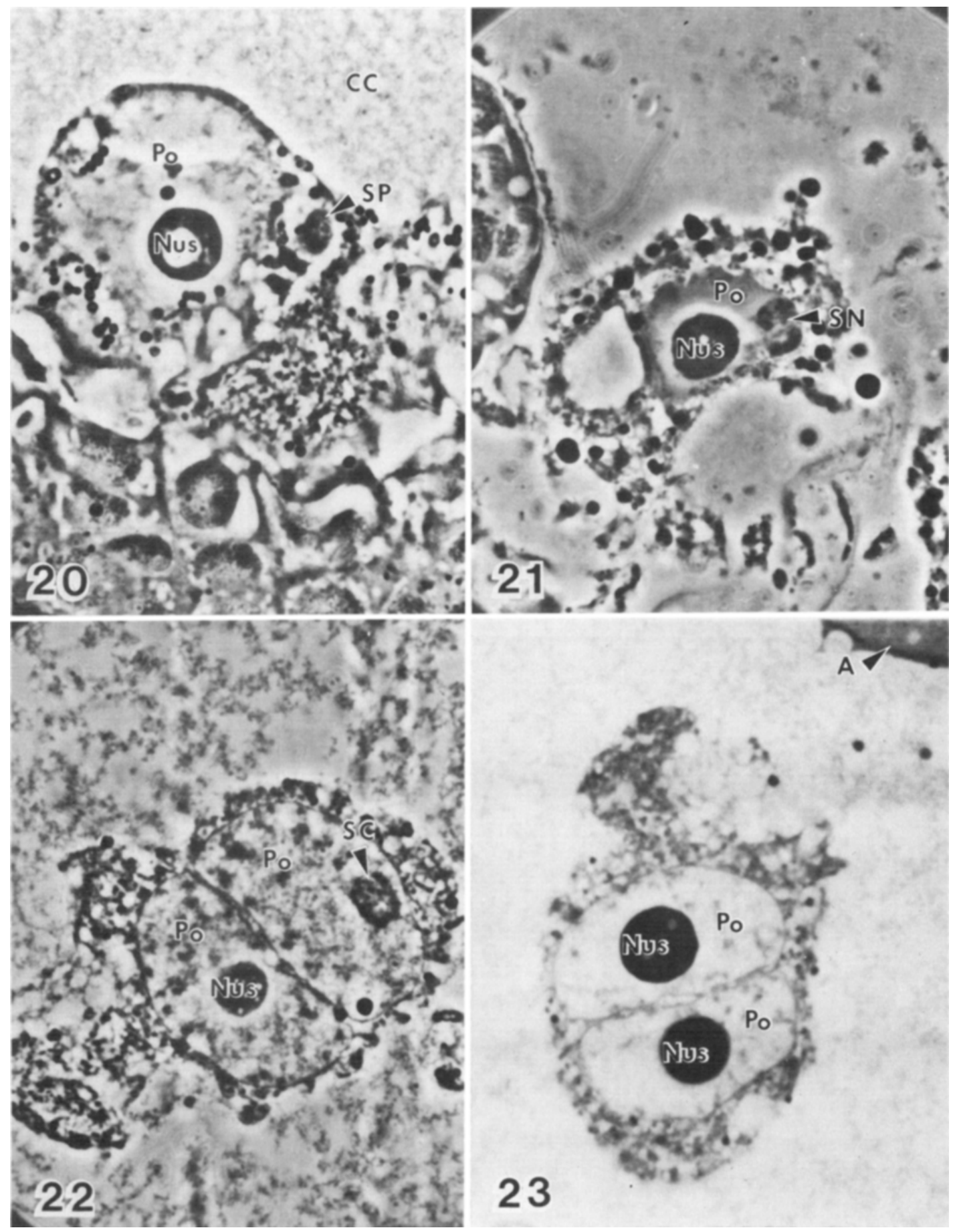


H. Lloyd Mogensen: Double fertilization in barley

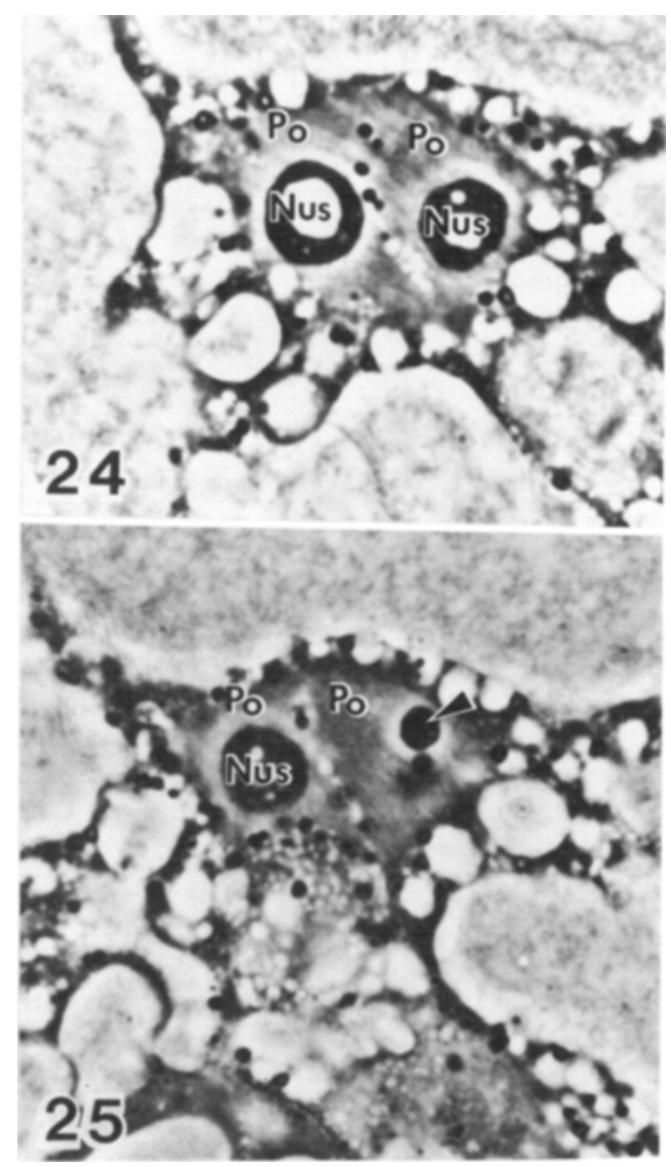


H. Lloyd Mogensen: Double fertilization in barley

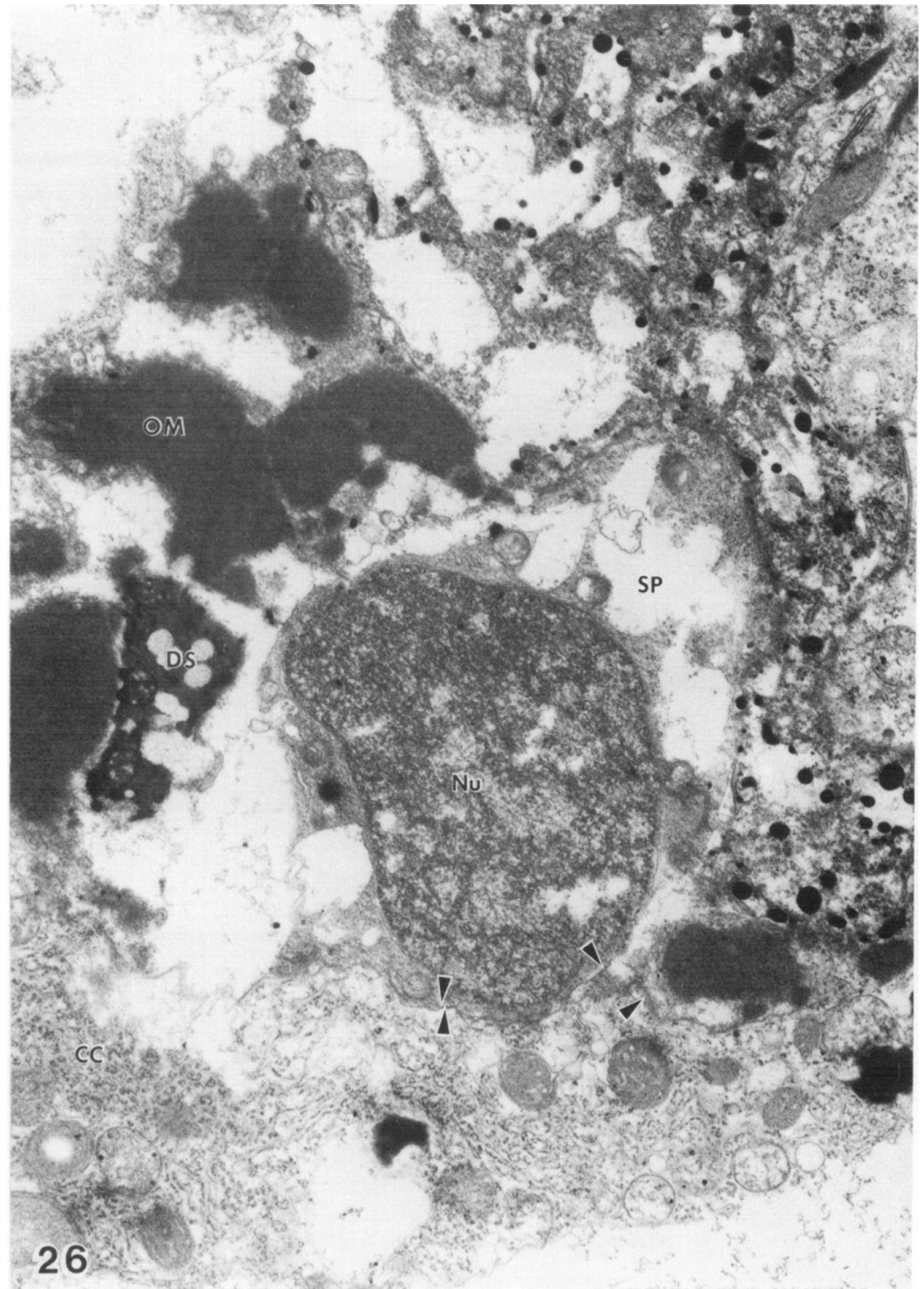




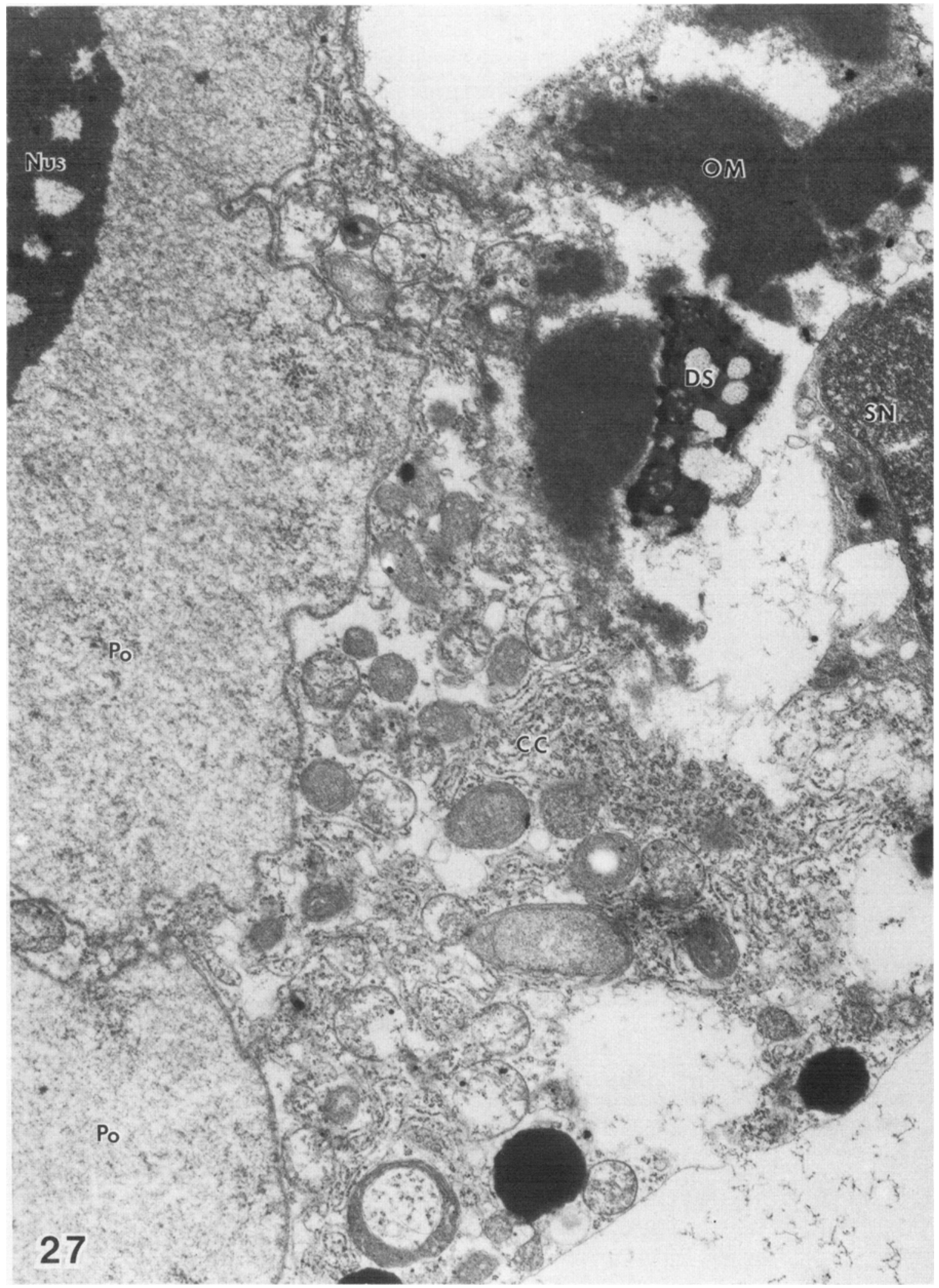




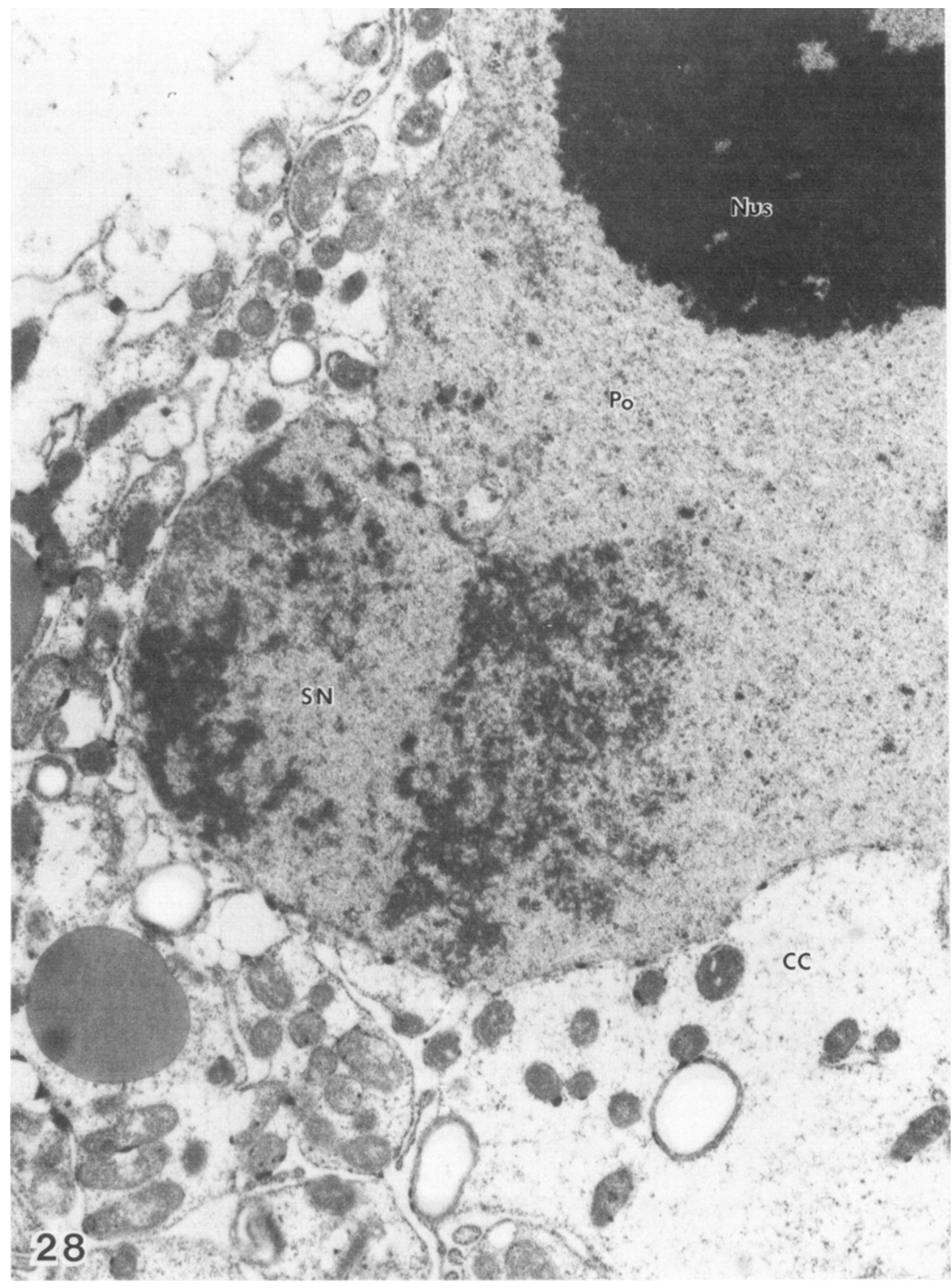




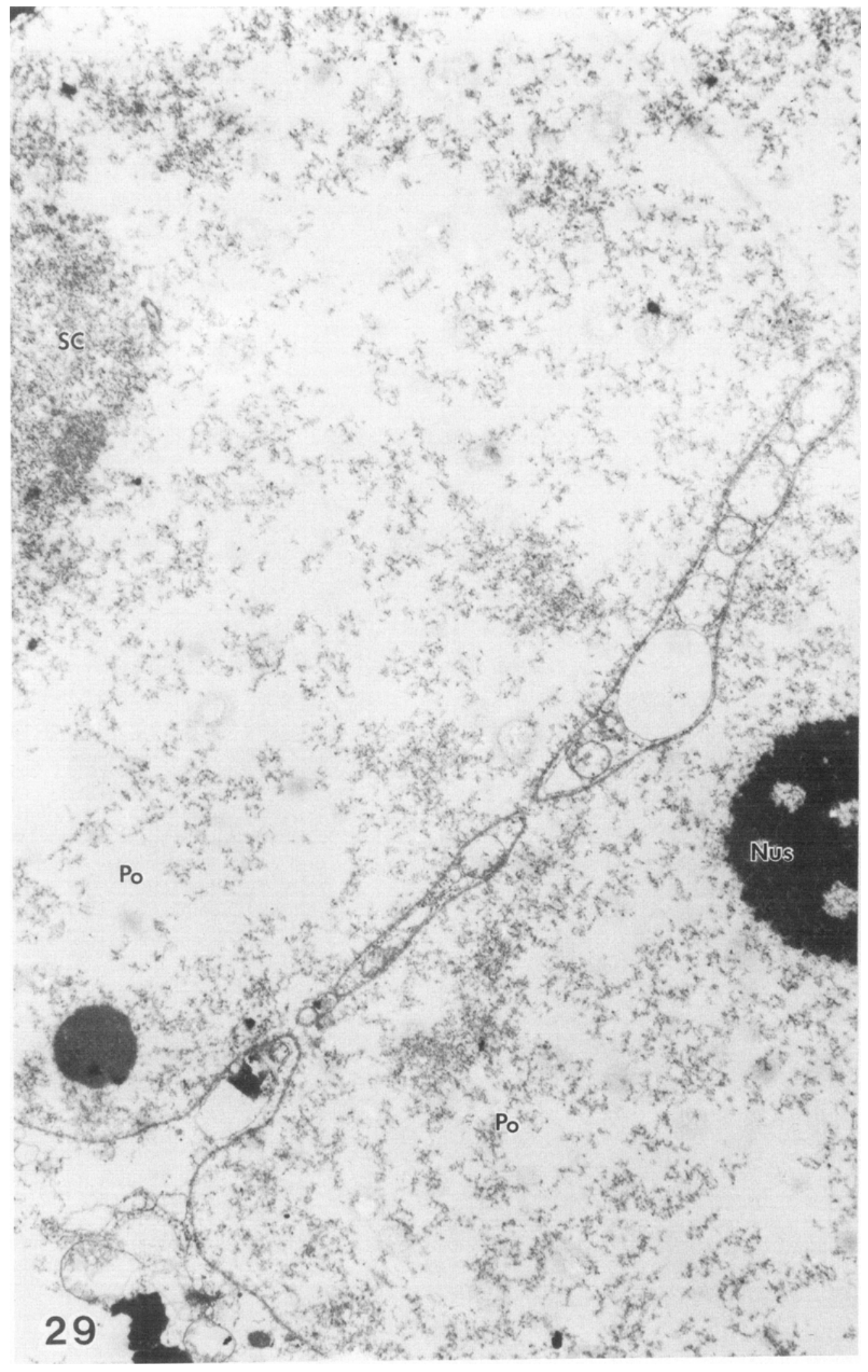




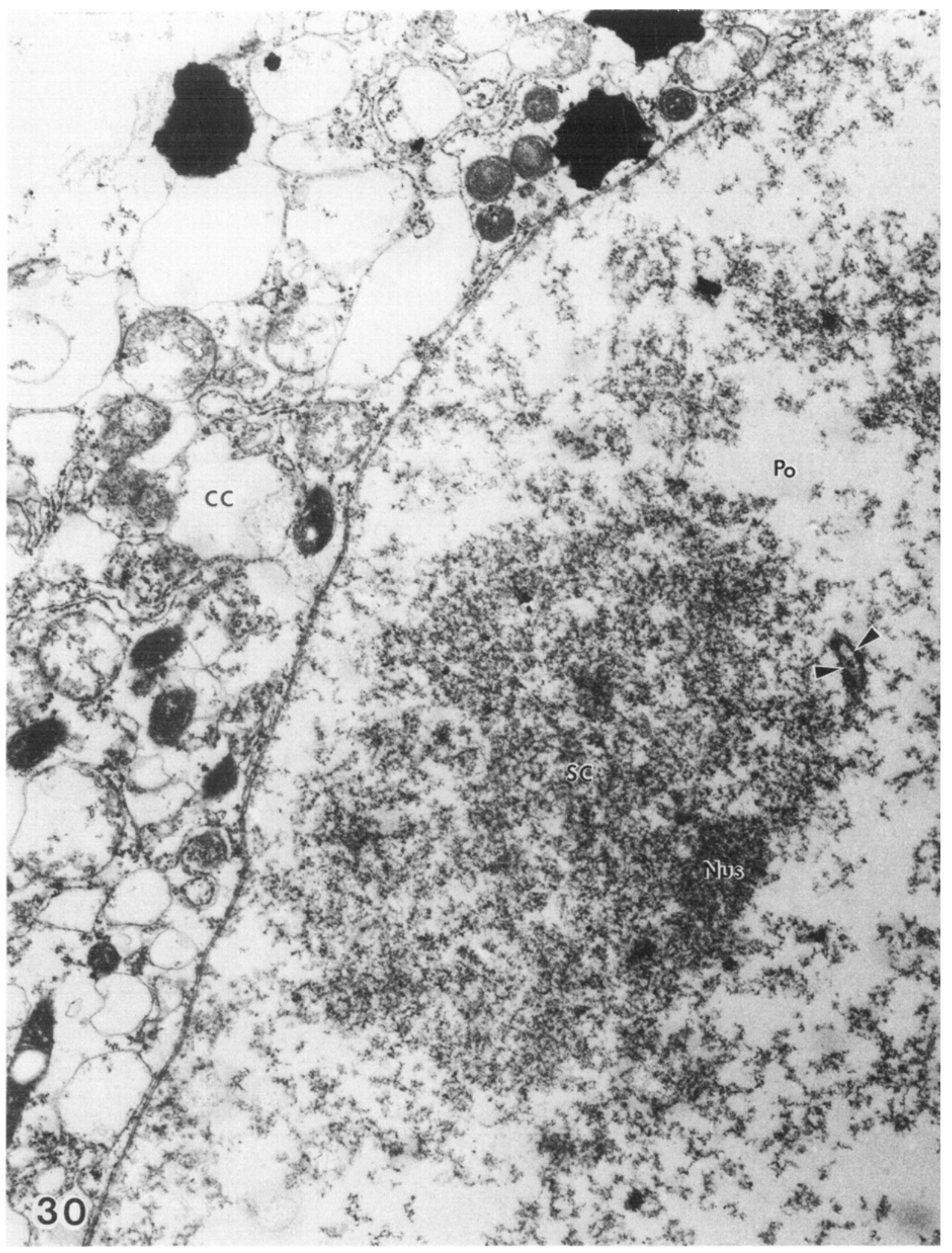




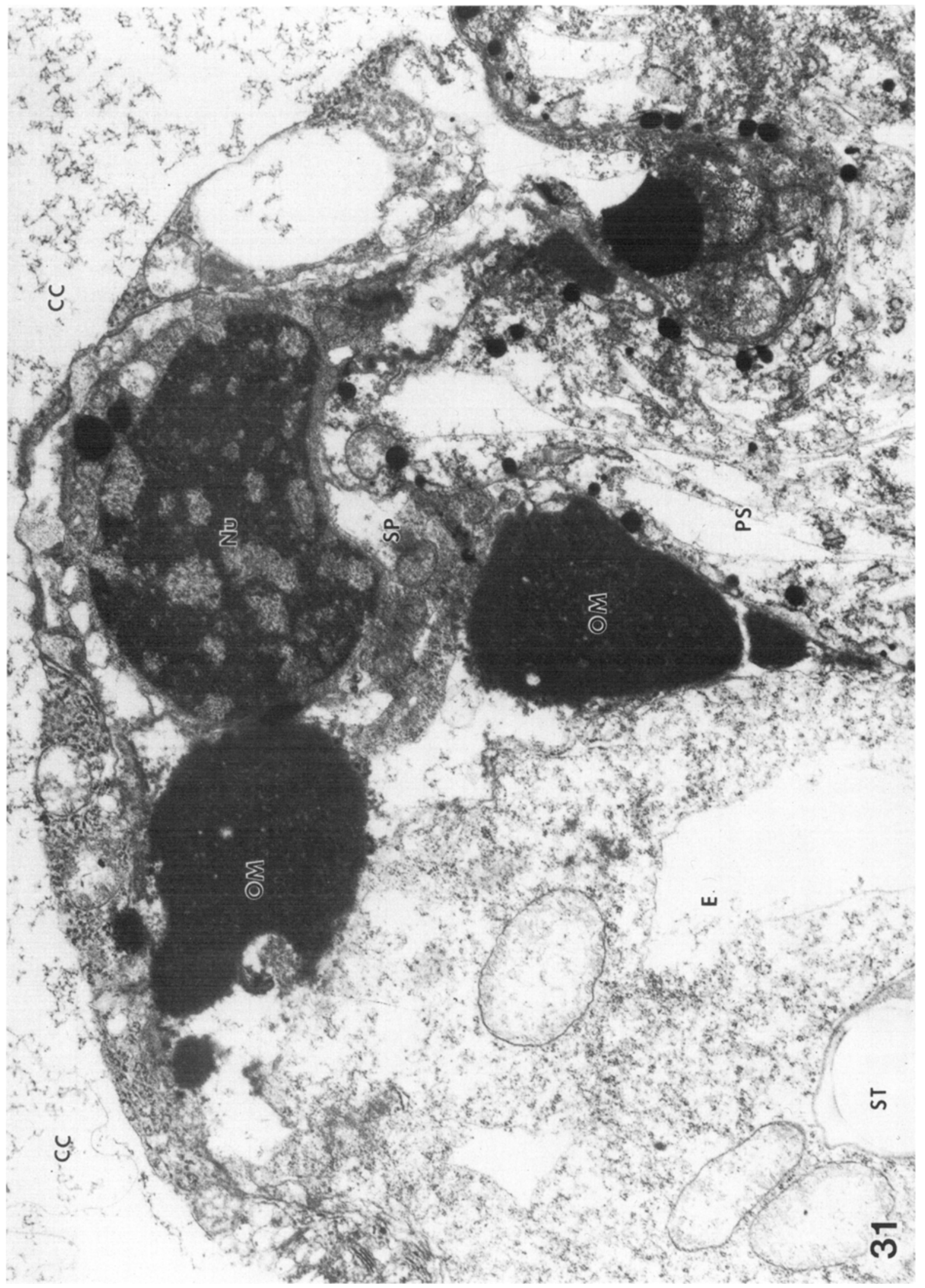




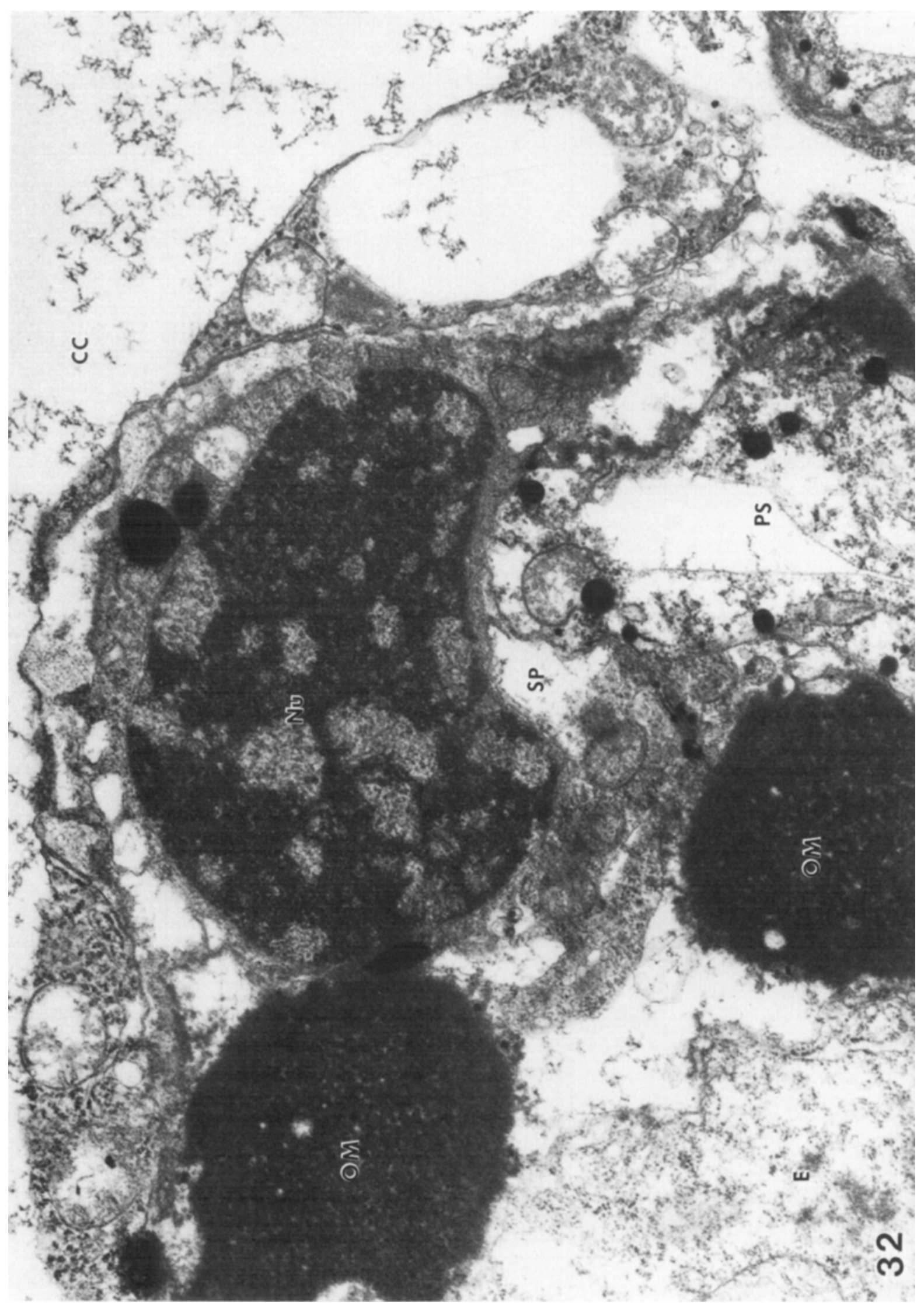




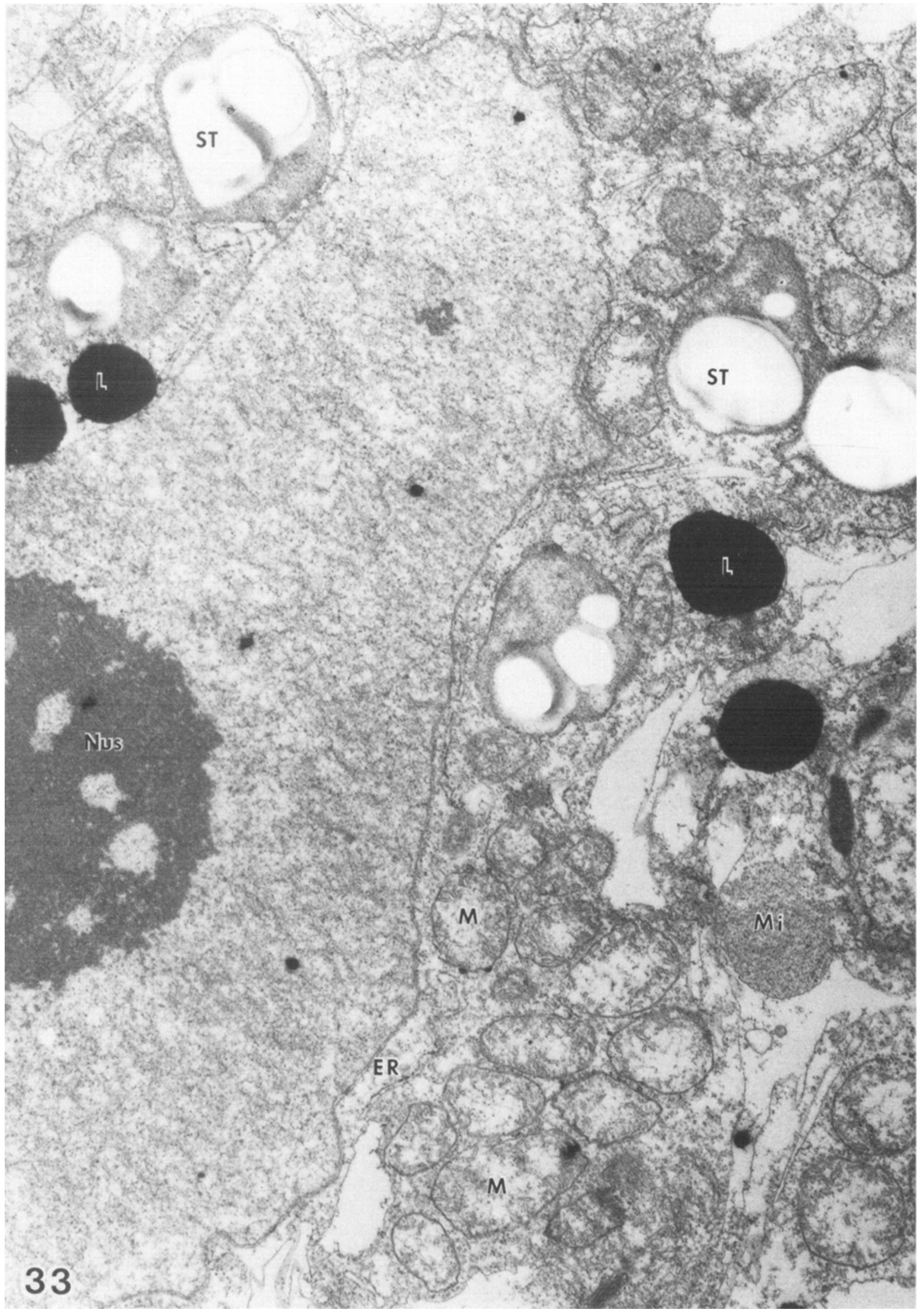




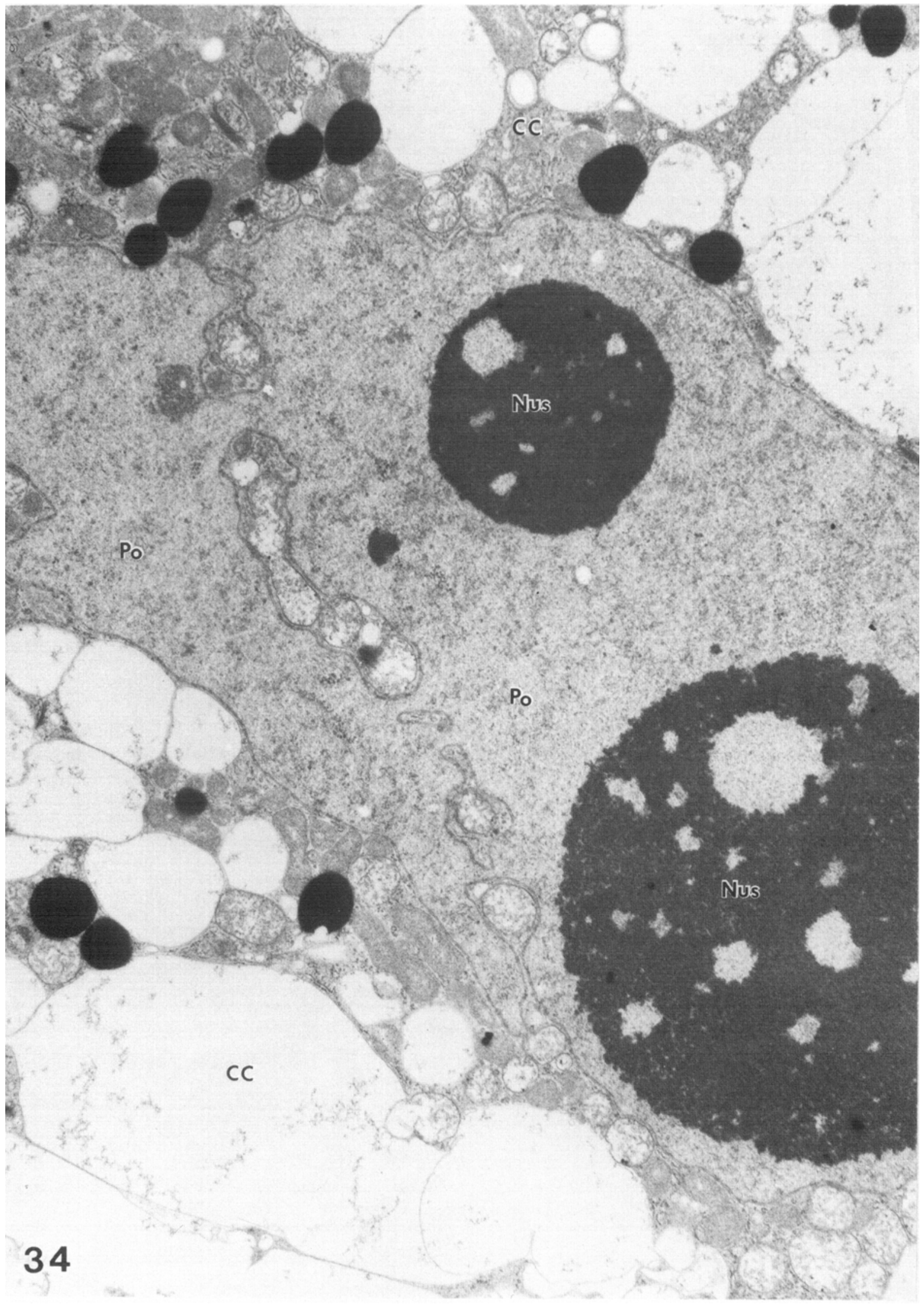




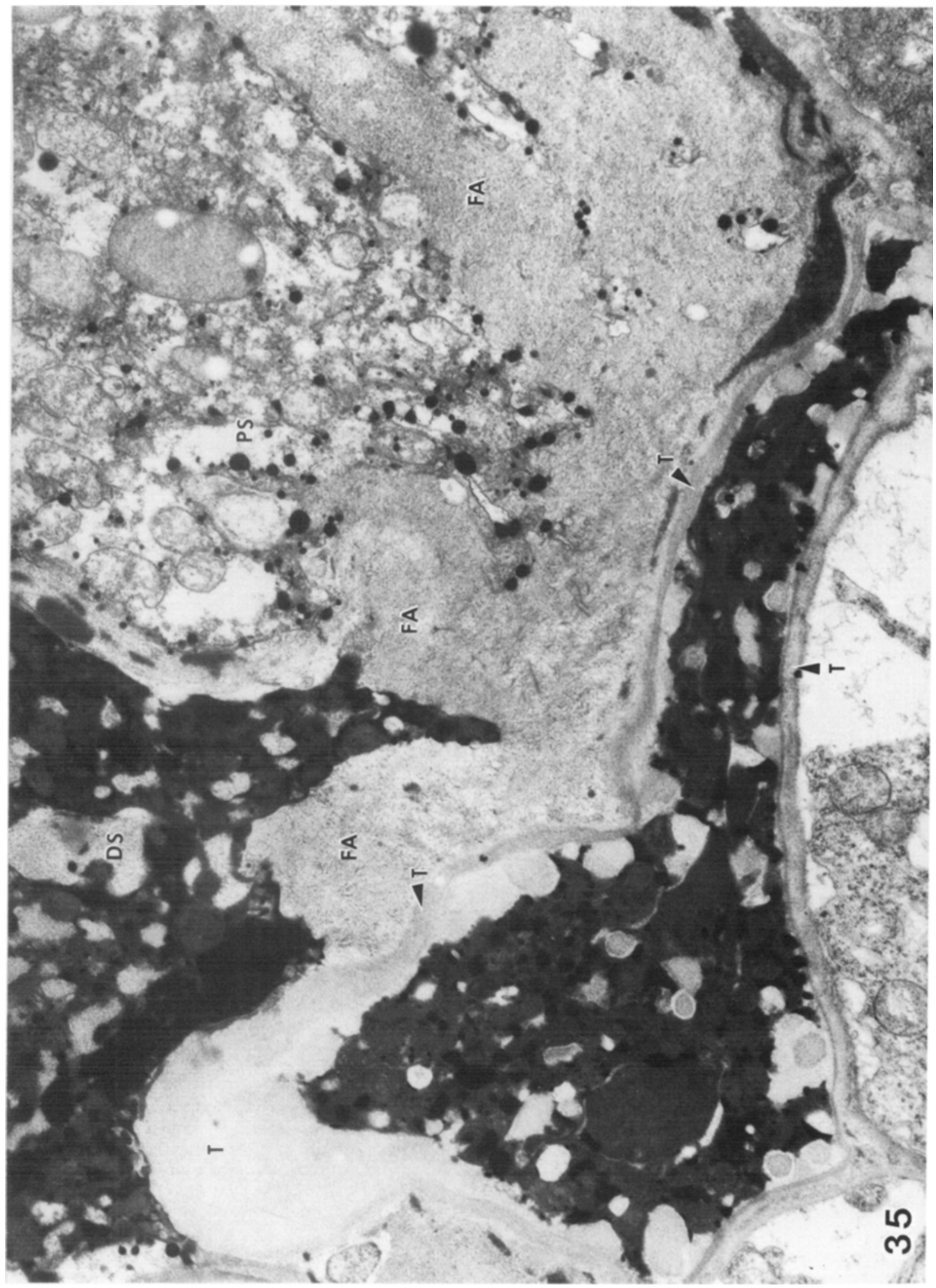




\section{H. Lloyd Mogensen: Double fertilization in barley}

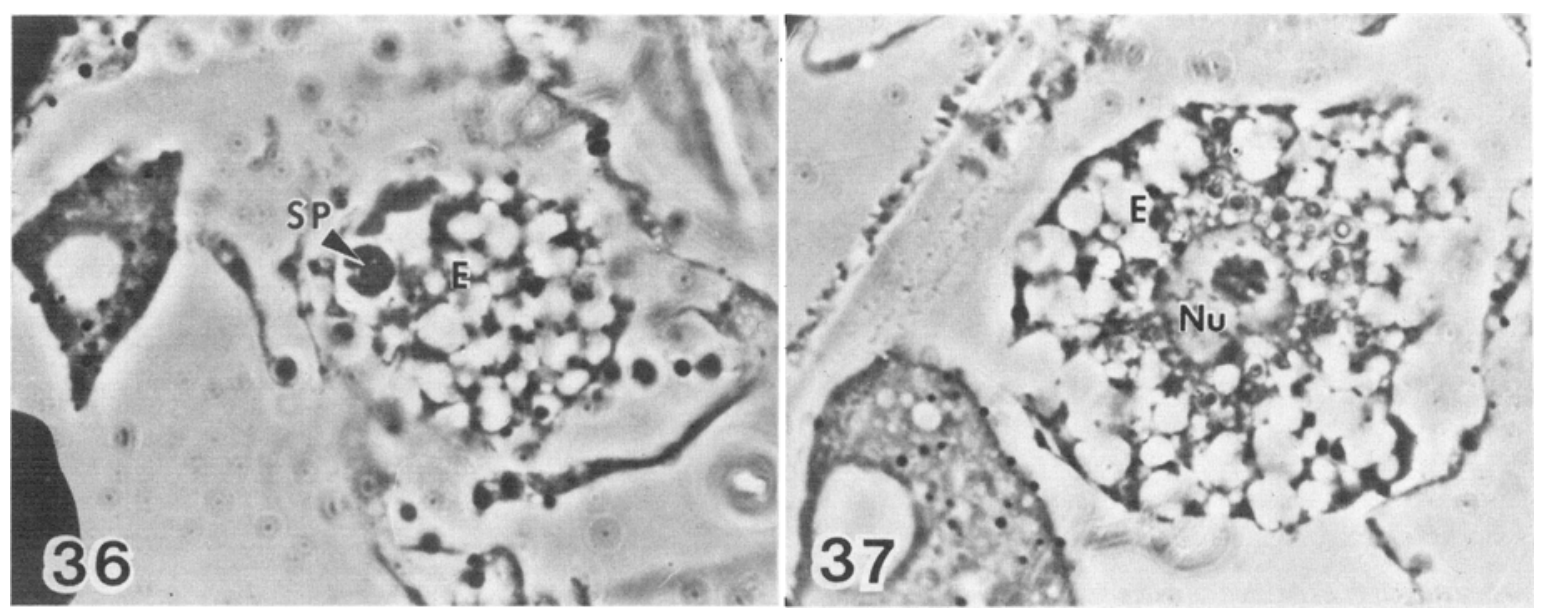




\section{H. Lloyd Mogensen: Double fertilization in barley}

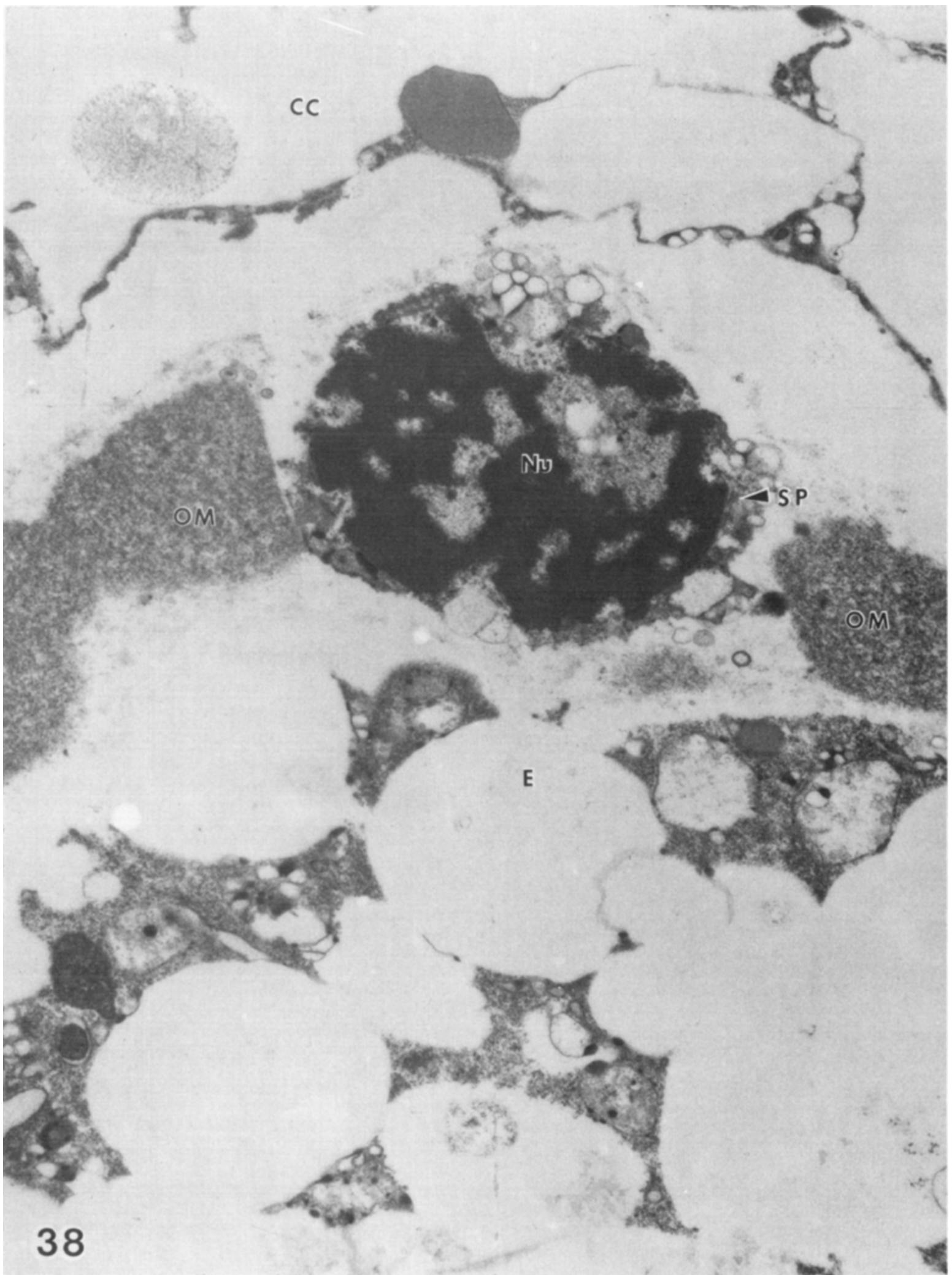




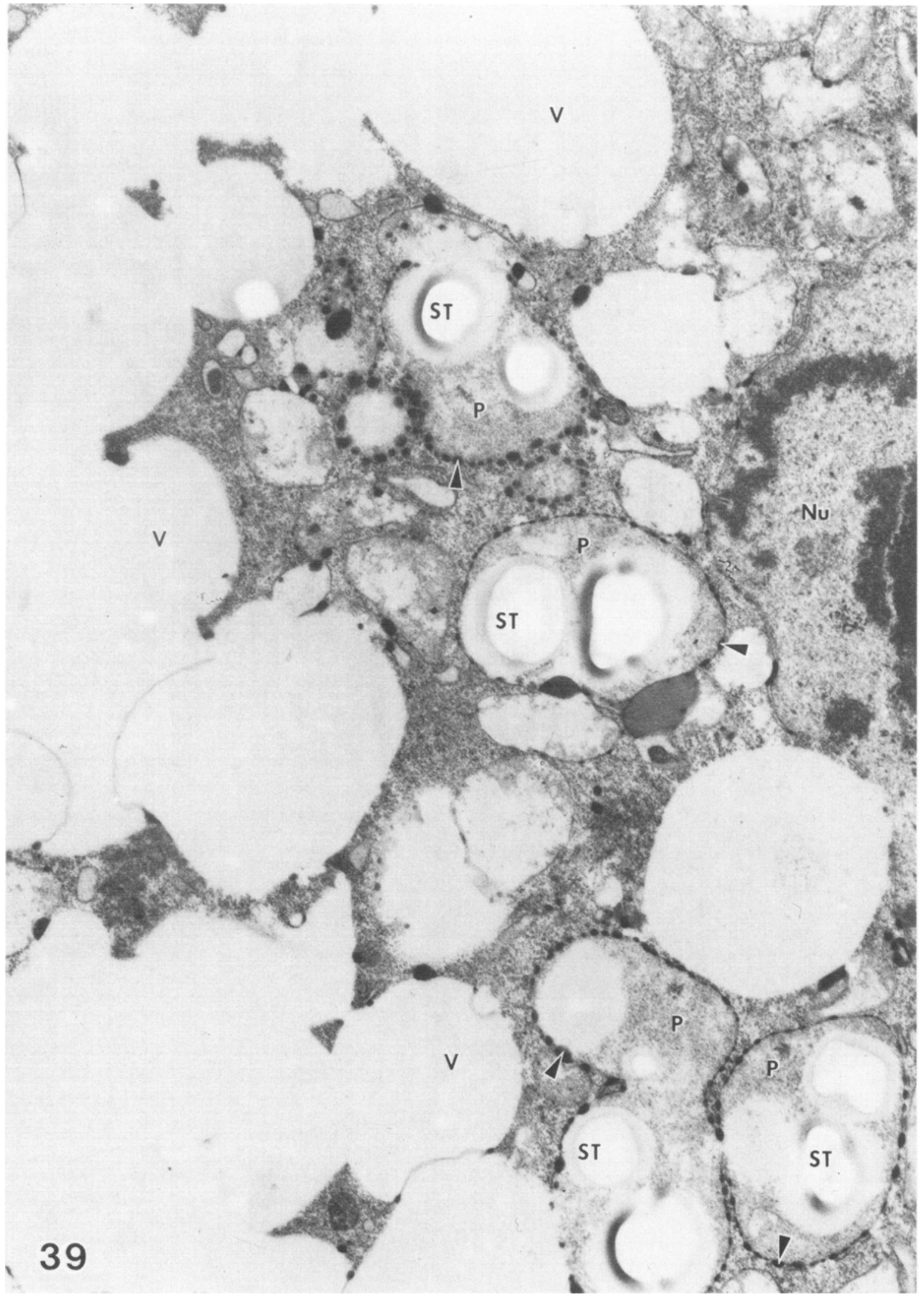



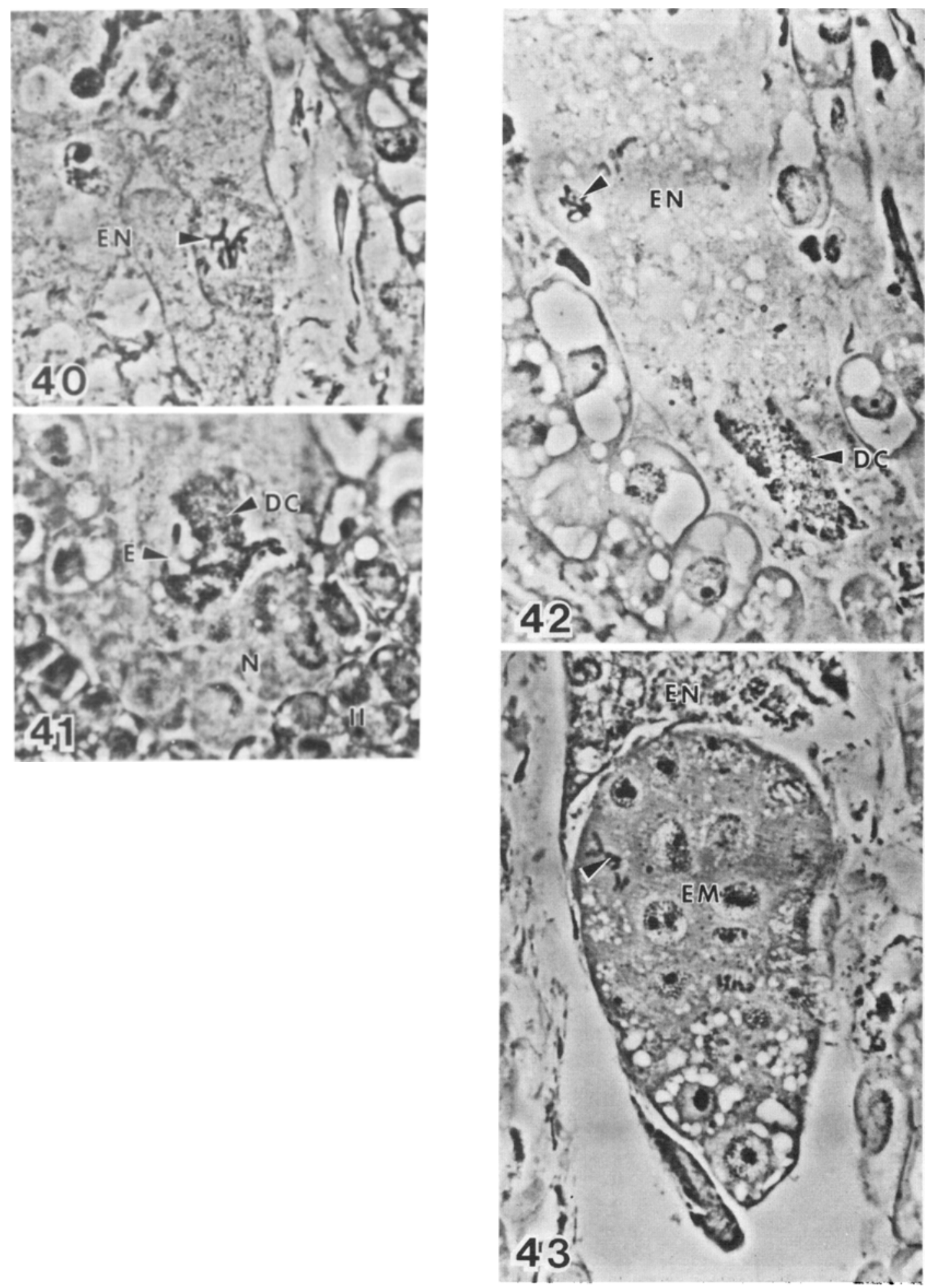


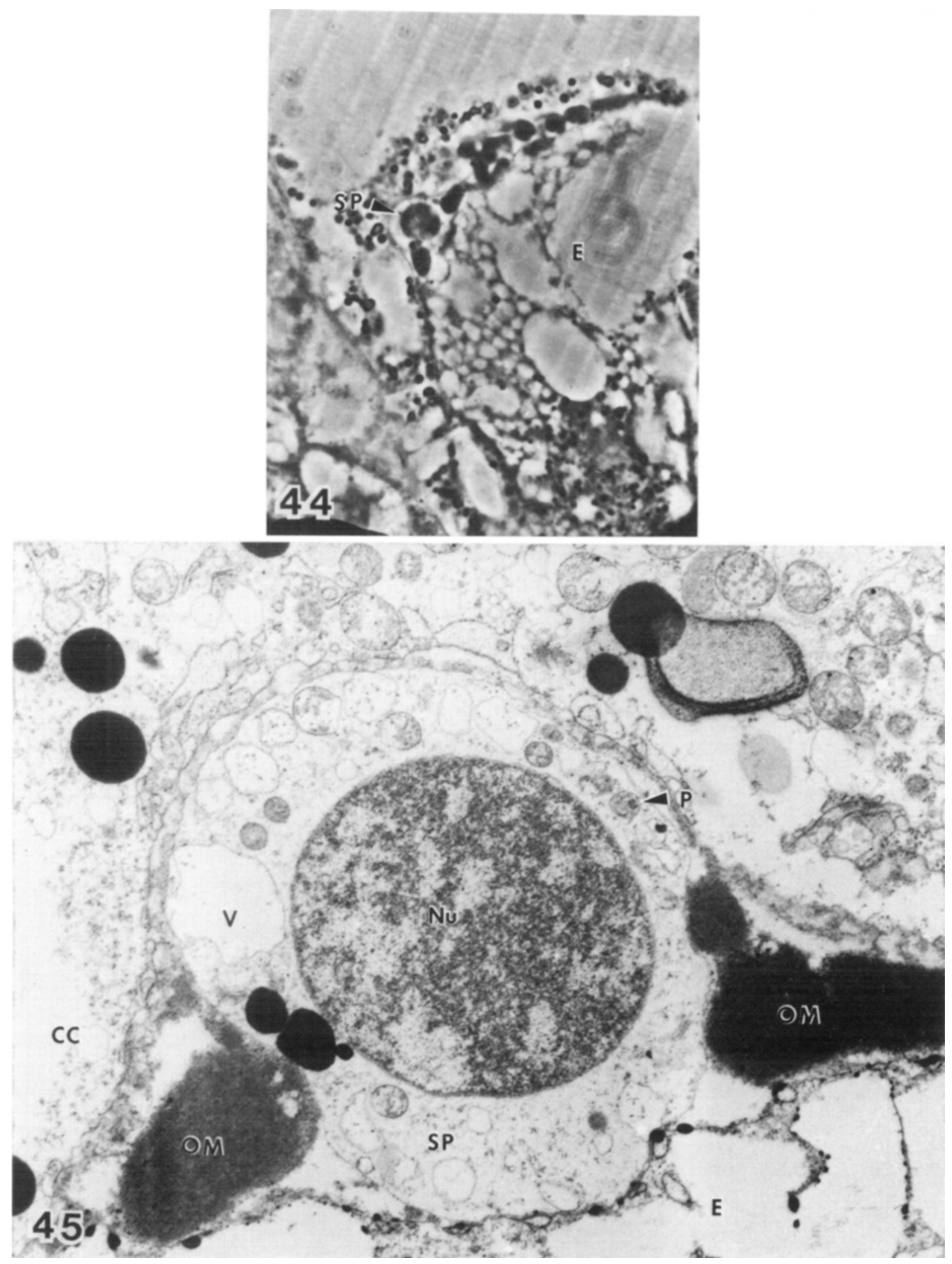




\section{H. Lloyd Mogensen: Double fertilization in barley}

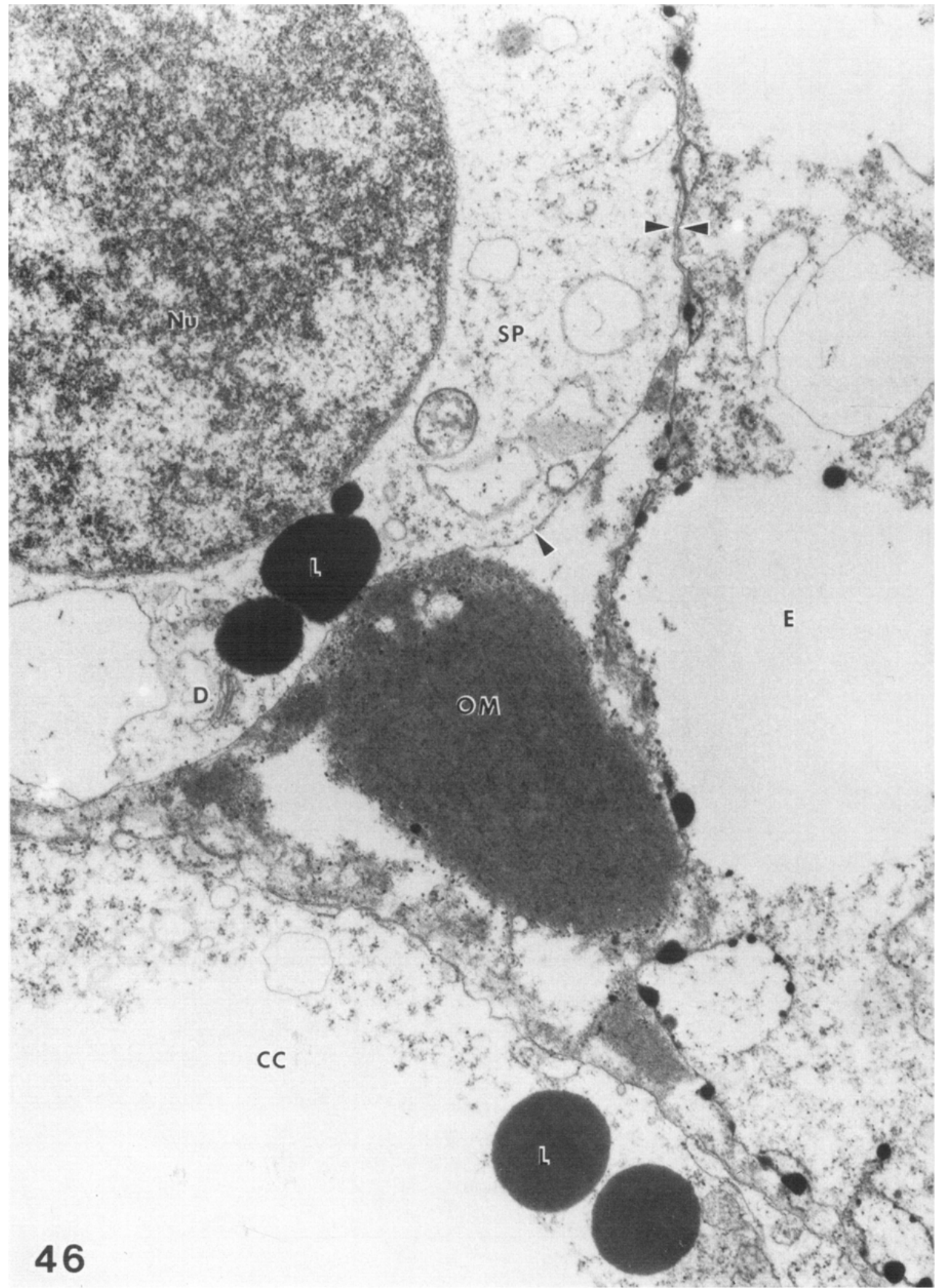

